Illinois State University

ISU ReD: Research and eData

Theses and Dissertations

6-20-2018

\title{
Is The Montessori Method A Solution To Improve Public Education? Comparing Two Pedagogical Models In Urban Schools
}

Iwona Beata Franczak

Illinois State University, iwonabfranczak@gmail.com

Follow this and additional works at: https://ir.library.illinoisstate.edu/etd

Part of the Sociology Commons

\section{Recommended Citation}

Franczak, Iwona Beata, "Is The Montessori Method A Solution To Improve Public Education? Comparing Two Pedagogical Models In Urban Schools" (2018). Theses and Dissertations. 924.

https://ir.library.illinoisstate.edu/etd/924

This Thesis is brought to you for free and open access by ISU ReD: Research and eData. It has been accepted for inclusion in Theses and Dissertations by an authorized administrator of ISU ReD: Research and eData. For more information, please contact ISUReD@ilstu.edu. 


\section{IS THE MONTESSORI METHOD A SOLUTION TO IMPROVE PUBLIC EDUCATION? COMPARING TWO PEDAGOGICAL MODELS IN URBAN SCHOOLS}

\section{IWONA BEATA FRANCZAK}

\section{8 pages}

Education is one of the most important social institutions that can improve quality of life. While our schools, ostensibly, provide for equal education for all, they differ in their curricula and resources that ultimately impact the quality of learning experiences. Distinguished educational organizations emphasize the need to implement our curricula with constructivist pedagogy. Montessori is a holistic educational model that embraces this approach. While studies show that Montessori methods provide positive outcomes for students, these studies are largely limited to performance of students attending private schools. The purpose of this work is to examine the effectiveness of public conventional and public Montessori schools with respect to student academic and social outcomes. Data on student academic performance derived from School Report Cards and data on student social competencies were obtained from the 5Essentials Survey Reports. The results suggest that overall students attending conventional schools outperformed academically students in Montessori schools and students who attended high income schools outperformed students who attended low income schools. In addition, a greater percentage of students who attended conventional schools exhibited self-control and responsibility while a greater percentage of students who attended Montessori schools displayed cooperation. Finally, data suggest a positive link between academic performance and social competencies. Sociological theories are discussed in attempts to understand the variation in 
student performance and explore fully the role of social class, race and ethnicity in shaping this performance.

KEYWORDS: Montessori schools, public schools, academic and social outcomes, sociological theories of education, education inequality, class and race in education 


\title{
IS THE MONTESSORI METHOD A SOLUTION TO IMPROVE PUBLIC EDUCATION? COMPARING TWO PEDAGOGICAL MODELS IN URBAN SCHOOLS
}

IWONA BEATA FRANCZAK

\author{
A Thesis Submitted in Partial \\ Fulfillment of the Requirements \\ for the Degree of \\ MASTER OF SCIENCE \\ Department of Sociology and Anthropology \\ ILLINOIS STATE UNIVERSITY
}


(C) 2018 Iwona Beata Franczak 
IS THE MONTESSORI METHOD A SOLUTION TO IMPROVE PUBLIC EDUCATION? COMPARING TWO PEDAGOGICAL MODELS IN URBAN SCHOOLS

IWONA BEATA FRANCZAK

COMMITTEE MEMBERS:

Richard D. Sullivan, Chair

Wilbert M. Leonard

Kyle Miller 


\section{ACKNOWLEDGMENTS}

No significant journey is ever undertaken alone. I would like to extend my sincere thanks and appreciation to the members of my committee and my family.

First of all, I would like to thank the Thesis Chair, Dr. Richard Sullivan, for making this research thesis possible. I am grateful for the guidance and support he offered me during this educational journey. I would like to thank him for sharing with me his expertise, engaging in stimulating dialogs, and allowing me to discover on my own what I was trying to accomplish. He is a great mentor who has inspired me to never settle for second best.

I would like also to thank the two other thesis committee members, Dr. Wilber Leonard and Dr. Kyle Miller, who shared with me insightful comments and provided constructive feedback. I am greatly appreciative of the time they spent reviewing my thesis and their words of support. I thank them for setting high standards and challenging me.

Finally and as importantly, I want to thank my husband and my family for their support in moments of doubts and discoveries. I thank them for being patient and giving me time to follow my passion. 


\section{CONTENTS}

Page

ACKNOWLEDGMENTS

TABLES vi

FIGURES viii

CHAPTER I: INTRODUCTION 1

Statement of Problem 1

Purpose of Study $\quad 4$

Research Questions $\quad 4$

Overview of Methods

The Case of Chicago $\quad 6$

$\begin{array}{ll}\text { Significance of Study } & 7\end{array}$

$\begin{array}{ll}\text { Personal Interest } & 8\end{array}$

Definition of Terms $\quad 11$

CHAPTER II: REVIEW OF LITERATURE 13

Educational System in the United States 13

$\begin{array}{ll}\text { History } & 13\end{array}$

$\begin{array}{ll}\text { Crisis in Education } & 14\end{array}$

Reasons Behind the Crisis 16

$\begin{array}{ll}\text { Responses to the Crisis } & 17\end{array}$

$\begin{array}{ll}\text { Montessori Approach } & 18\end{array}$

$\begin{array}{ll}\text { Overview of the Method } & 18\end{array}$

$\begin{array}{ll}\text { History } & 20\end{array}$

Studies on Effectiveness of Montessori Model in Public School 21 
Theoretical Framework

$\begin{array}{ll}\text { Status Attainment Theory: Blau and Duncan } & 24\end{array}$

$\begin{array}{ll}\text { Educational Value Theory: Roslyn Mickelson } & 26\end{array}$

Oppositional Culture Theory: John Ogbu 27

Theory of Profiling and Labeling: Glida Ochoa 30

De Facto Segregation: Jonathan Kozol 31

Social Reproduction: Pierre Bourdieu 33

$\begin{array}{ll}\text { CHAPTER III: METHODOLOGY } & 37\end{array}$

$\begin{array}{ll}\text { Data } & 37\end{array}$

$\begin{array}{ll}\text { Data Strengths } & 37\end{array}$

$\begin{array}{ll}\text { Population and Procedure } & 37\end{array}$

$\begin{array}{ll}\text { Sample } & 43\end{array}$

$\begin{array}{ll}\text { Measures } & 43\end{array}$

Illinois School Report Cards and Academic Performance 44

The 5Essentials Survey Reports and Social Competence $\quad 44$

Academic Performance $\quad 45$

$\begin{array}{ll}\text { Social Competence } & 47\end{array}$

$\begin{array}{ll}\text { Case Measures } & 48\end{array}$

$\begin{array}{lr}\text { CHAPTER IV: ANALYSIS } & 50\end{array}$

$\begin{array}{ll}\text { Introduction } & 50\end{array}$

Descriptive Analysis $\quad 52$

$\begin{array}{ll}\text { Comparative Analysis } & 53\end{array}$

Descriptive Analysis $\quad 54$ 
Academic Performance in Math and ELA 56

$\begin{array}{lr}\text { Social Competence } & 59\end{array}$

$\begin{array}{ll}\text { Comparative Analysis } & 60\end{array}$

$\begin{array}{ll}\text { Comparison of Montessori and Conventional Schools } & 61\end{array}$

Comparison of Low Income Schools: MLI-CLI 63

Comparison of High Income Schools: MHI-CHI 65

Comparison of Schools with Different Demographics: MLI-CHI 67

Comparison of Schools with Different Demographics: MHI-CLI 69

Comparison of Academic Performance and Social Competence Combined $\quad 70$

$\begin{array}{ll}\text { CHAPTER V: DISCUSSION } & 75\end{array}$

$\begin{array}{ll}\text { Introduction } & 75\end{array}$

$\begin{array}{ll}\text { Summary of Findings } & 77\end{array}$

$\begin{array}{ll}\text { School Characteristics } & 77\end{array}$

$\begin{array}{ll}\text { Academic Performance } & 79\end{array}$

$\begin{array}{ll}\text { Social Competence } & 81\end{array}$

$\begin{array}{ll}\text { Research Questions } & 83\end{array}$

$\begin{array}{ll}\text { Discussion of Findings } & 84\end{array}$

$\begin{array}{ll}\text { Characteristics of Schools } & 84\end{array}$

$\begin{array}{ll}\text { Academic Performance } & 86\end{array}$

$\begin{array}{lr}\text { Social Competence } & 88\end{array}$

Link Between Academic Performance and Social Competence $\quad 90$

$\begin{array}{ll}\text { School Funding } & 90\end{array}$ 
$\begin{array}{ll}\text { Limitations } & 91\end{array}$

$\begin{array}{ll}\text { Ethical Issues } & 93\end{array}$

$\begin{array}{ll}\text { Anonymity and Confidentiality } & 93\end{array}$

$\begin{array}{ll}\text { Implications } & 94\end{array}$

$\begin{array}{ll}\text { Future Research } & 96\end{array}$

$\begin{array}{ll}\text { CHAPTER VI: CONCLUSION } & 98\end{array}$

$\begin{array}{ll}\text { REFERENCES } & 100\end{array}$

APPENDIX A: STUDIES ON ACADEMIC PERFROMANCE IN MONTESSORI SCHOOLS 107

APPENDIX B: STUDIES ON SOCIAL COMPETENCE 110

APPENDIX C: DATA FOR DESCRIPTIVE ANALYSIS 112

APPENDIX D: DATA ON SOCIAL COMPETENCE 116

APPENDIX E: DATA FOR COMPARATIVE ANALYSIS 118 


\section{TABLES}

Table

Page

1. School Characteristics in Percentages by School

2. PARCC Score and Levels

46

3. Teacher 5Essentials Survey $\quad 47$

4. Characteristics of School Population in Percentages by School 55

5. MLI: Math-ELA Expectations $\quad 57$

6. MHI: Math-ELA Expectations $\quad 58$

7. CLI: Math-ELA Expectations 58

8. CHI: Math-ELA Expectations 59

9. Social Competence in Percentages by School 60

10. Characteristics of the Montessori and Conventional School Groups in Percentages 62

11. Montessori Schools-Conventional Schools: Academic Performance 63

12. Social Competence: MS-CS 63

13. Characteristics of Low Income Montessori and Conventional School Groups in $\begin{array}{ll}\text { Percentages } & 64\end{array}$

14. MLI-CLI Academic Performance $\quad 64$

15. Social Competence: MLI-CLI 65

16. Characteristics of High Income Montessori and Conventional School Groups in Percentages

17. MHI-CHI Academic Performance $\quad 67$

18. Social Competence: MHI-CHI 67 
19. Characteristics of High Income Montessori and Conventional School Groups in Percentages

20. MLI-CHI Academic Performance

21. Social Competence: MLI-CHI

22. Characteristics of High Income Montessori and Low Income Conventional School in Percentages

23. MHI-CLI Academic Performance

24. Social Competence: MHI-CLI

25. Academic Performance and Social Skills: MS-CS

26. Academic Performance and Social Skills: MLI - CLI

27. Academic Performance and Social Skills: MHI-CHI

28. Academic Performance and Social Skills: MHI-CLI

29. Academic Performance and Social Skills: MLI-CHI

30. Social Competence in Percentages by School 


\section{FIGURES}

Figure $\quad$ Page

1. Sections of Analysis $\quad 51$

2. Analytical Levels of Performance 52

3. Social Skills 53

4. Comparisons $\quad 54$ 


\section{CHAPTER I: INTRODUCTION}

"Humanism will affirm life rather than deny it, seek to elicit the possibilities of life, not flee from it, and endeavor to establish the conditions of satisfactory life for all, not merely for the few" (American Humanist Association 2018).

The humanistic hope is that each individual can live a satisfactory life. While meritocracy implies that our success is the result of individual talents, hard work, and commitment, studies continue to show that our ascribed characteristics such as socioeconomic background, gender, race and ethnicity greatly impact the quality of our life (Ballantine and Hammock 2012). These ascribed attributes are more advantageous for some than they are for others.

Since we cannot change our disadvantageous ascribed characteristics, education becomes one of the most important social institutions that can improve quality of life, especially for those who are traditionally at risk for personal, professional, and economic failure. In the USA, public schools are considered a great equalizer (Putnam 2015) and according to law, we cannot be discriminated against in our access to education based on race, ethnicity, and gender (Brown v. Board of Education 1954; Equal Educational Opportunities Act 1974). Also, studies confirm that those who finish high school are more likely to experience positive professional and personal outcomes (Fredricks, McColskey, Meli, Mordica, Montrosse, and Mooney 2011).

\section{STATEMENT OF PROBLEM}

School age children constitute a significant and growing part of the American population. In 2016, about 55.6 million students attended elementary and secondary schools in the United States (US Dept of Education 2016). Approximately, 90 percent of students attended public schools. Studies reveal that a substantial number of these students enter our public schools lagging in both reading and math skills (Garcia and Weiss 2015). This skill gap is strongly correlated with student's race and social class. As such, poor children face significant obstacles 
to success. Studies reveal that Black and Hispanic students have the greatest disadvantages in math and reading due to their minority status and social class. The low social class status not only affects academic performance but has negative consequences on student social and noncognitive skills such as self-control or interactions with peers and teachers (Garcia and Weiss 2015).

Those who struggle academically and socially during the early years of their formal education are less likely to do well in high school and are more likely to drop out of school (Fredricks et al.2011). National data show that those who do not complete high school have fewer opportunities for employment and are more prone to poverty, bad health and criminal activity (Fredricks et al. 2011). In 2015, the National Center for Education Statistics ([NCES] 2016) reported that the dropout rate for students ages 16 through 24 was 5.9 percent and impacted 2.7 million individuals (US Dept of Education 2016). The dropout rate was the lowest for white individuals (4.6 percent) and those with family income in the highest quartile (2.4 percent). The highest dropout rate was for Hispanics (9.2 percent) and those with the family income in the lowest quartile (9.9 percent) (NCES 2016).

In the USA, public education has a long history (Bennett deMarrais and LeCompte 1995; Putnam 2015). Public schools are free, funded by the government and depend on local property taxes. Since government provides the funds for public schools, it also dictates schools' educational standards and assessments that have to be met in order for schools to receive funds. Students then are required to perfect particular knowledge by specific ages and their progress is measured by standardized tests (Martin 2004). As a result, the operation of most public conventional schools is oriented around a fixed curriculum that prepares students to take tests and views teachers as a source of authority and enforcer of discipline (Goslin 2003). Students of 
similar ages (and sometimes abilities) are grouped together in one classroom, engage in listening to lectures or completing assigned tasks in 45 minute blocks, and rely on teachers' instructions and textbooks.

Poor tests performance of students attending conventional low income schools has led to debate concerning the state of public schools in the USA (Broussard 2016). As a result, some public schools have adopted a Montessori approach to education. Since those schools are public, student performance is also assessed by standardized tests and school funding depends on students' scores on standardized tests and local property taxes. However, in contrast to conventional schools, Montessori approach provides child-centered and holistic curricula, students work in mixed age groups on chosen activities in three hours blocks of uninterrupted time, and use specifically designed educational materials (Lillard 2012). While Montessori approach recognizes the importance of teachers' authority in the process of students' development, teachers in Montessori schools act as guides who offer students constructive activities that further enhances their capacities (Tzuo 2007).

In the USA, the Montessori approach became popular in the 1960s. While most Montessori schools are private, there are some public schools that adopt this approach. Studies show that Montessori schools are successful in providing students with high quality education and positive academic (Clifford and Takacs 1991; Erwin, Wash, and Mecca 2010; Karnes, Shwedel, and Williams 1983; Jones and Miller 1979; McDurham 2011; Miller and Bizzell 1983; Miller and Bizzell 1984; Moody and Riga 2011, Lillard and Else-Quest 2006, Lillard 2012; Peng 2009) and socio-behavioral outcomes (Ervin et al. 2010; Lillard and Else-Quest 2006; Lillard 2012). 


\section{PURPOSE OF STUDY}

The purpose of this study is to compare conventional and Montessori educational models with respect to academic and social outcomes. Literature on academic performance clearly indicates that those who do well academically are more likely to complete high school and have more opportunities for employment (Fredricks et al. 2011). This ultimately decreases their chances of experiencing poverty, bad health, or criminal activity. While schools are vehicles for students' academic achievement, we often forget that schools also offer students various opportunities for developing social competencies. Literature on social competencies reveals that developing social skills is necessary for healthy and successful navigation of social environments as well as it has positive impact on our personal and professional outcomes (Durlak, Weissberg, Dymnicki, Taylor, Schellinger 2011).

Since student outcomes are greatly associated with their parents' socioeconomic status and most Montessori schools are private (NAMTA 2018), this work focused on the Montessori and conventional models in a public schools to reduce the influence of socioeconomic differences. The research design involved selecting four public schools - two conventional and two Montessori - to compare differences in academic and social outcomes between the two curricular approaches.

\section{RESEARCH QUESTIONS}

1. How do students perform academically in public schools that implement a Montessori model compared to students who attend conventional public schools?

2. What are the outcomes regarding social competencies of students who attend public schools that implement a Montessori model compared to students who attend conventional public school? 


\section{What is the link between students' academic performance and their social}

competencies? Does it differ between students who attend schools that implement a Montessori model and conventional model?

\section{OVERVIEW OF METHODS}

This study consisted of two parts. The first part examined student academic achievement and the second explored student outcome of social competence. The first part compared academic performance of students attending two conventional schools (CS) to academic performance of students attending two Montessori elementary schools (MS). All four schools were located in one school district within a close proximity to each other in the city of Chicago.

Two conventional schools, in as much as two Montessori schools, differed from each other in student demographic composition. One school had a student population with more advantageous demographics (high income school) and the other school had a student population with less advantageous demographics (low income school).

Next, I compared academic performance of students attending low income Montessori (MLI) to academic performance of students attending low income conventional elementary school (CLI). Then the academic performance of high income Montessori school (MHI) was compared to academic performance of students attending high income conventional elementary school (CHI). The second part of this research studied the same groups but compared and contrasted student social competence.

Researchers have found that student outcomes are greatly associated with their parents' socioeconomic status. Therefore, examining student performance in pairs of schools attended by students with similar socioeconomic status allowed me to determine how socioeconomic status affects student performance. On the other hand, by controlling for student demographics, I was 
in a better position to determine the effectiveness of conventional and Montessori models. Other variables such as teacher experience, class size, parent involvement, and absenteeism are important factors in assessing the effectiveness of learning models but due to time constraints and the scope of this study, these variables were not analyzed.

\section{THE CASE OF CHICAGO}

I decided to set my research in Chicago Public Schools for three primary reasons. Chicago is one of the largest cities in the U.S., shares a history with Maria Montessori and is located in one of the first states to implement the Every Student Succeeds Act (ESSA).

Chicago as a large city in the U.S. is composed of a diverse population. It is also one of twelve cities with the densest cluster of public Montessori schools in the U.S. In Illinois, there are nine public schools with Montessori programs and six of them are clustered in Chicago (US Montessori Census 2017).

Chicago has an important place in the history of Montessori in the U.S. Jane Adams, a well known social activist and co-founder of the Hull House, met Maria Montessori in Italy when visiting the Children's House in 1910. Both women shared compassion for the disadvantaged and recognized the importance of education in their life. In 1915, Maria Montessori visited the Hull House and attended John Dewey's talk on democratic society and education organized by Jane Adams (Zell 1997). Maria Montessori not only became a good friend of Jane Adams and John Dewey but also trained women who lived in Hull House in her educational philosophy (Zell 1997).

Finally, of special interest of mine is also Illinois legislative action implementing the President Obama's initiative called Every Student Succeeds Act (ESSA) that amended the Elementary and Secondary Education Act of 1965. Literature reveals that Illinois is actually one 
of the first states to identify non-academic standards that now are a part of the Common Core and serve as a model for other states in establishing their standards (Durlak et al. 2011). The Illinois' standard goals address student's social - emotional learning and hope to provide students with self-awareness and self-management skills to achieve school and life success, use socialawareness and interpersonal skills to establish and maintain positive relationships, and demonstrate decision-making skills and responsible behaviors in personal, school, and community contexts (Illinois State Board of Education [ISBE] 2017).

SIGNIFICANCE OF STUDY

With a substantial number of students attending and entering public schools, improving the attainment rates among our most disadvantaged youth not only affect a large group of individuals but is a matter of national importance with significant implications for the students and society.

In the light of current debates surrounding the state of public schools in the USA and a desire to improve performance, current political powers push for school choice through charter schools and vouchers. While charter schools, similarly to magnet schools, might orient themselves around particular academic themes such as math or arts, they differ from traditional public schools and magnet schools in the ways they are funded and governed. Specifically, charter schools receive both public and private funding. They have a greater independence from school districts than other public schools have and report to charter boards such as private firms who fund the school (National Charter School Resource Center [NCSRC] 2017). School vouchers are designed to help students to pay for attending private schools (NCSRC 2017).

On the other side of the debate, the constructivist approach in education promotes a childcentered focus that appreciates students' culture and past experiences. Early education 
organizations such as the National Association for the Education of Young Children (NAEYC), the New Commission on the Skills of the American Workforce, the National Association for the Education of Young Children (NAEYC), or the Institute for Research and Reform in Education (IRRE) emphasize the need to augment current curricula with the age-appropriate developmental practices, demanding but feasible assignments, and constructive approaches to education (Chauncey and Wasler 2009). This approach is based on the belief that learning is an active and constructive process (Mordechai 2009). Experiences become the foundation of knowledge that is constructed based on students' interpretation of those experiences. The Montessori model is an example of a constructivist approach.

While there is a substantial body of research addressing learning experiences in Montessori schools, there is limited work that compares public Montessori to Conventional elementary schools. The present work, therefore, can expand our understanding of the current status of Montessori-based public schools. The hope for this study was to help us identify areas within this educational model that work well in public formats or need improvement so we can provide young students with an education that fosters their full potential.

\section{PERSONAL INTEREST}

Before I had the opportunity to return to school to pursue my bachelor's degree, I worked in the legal field for about eight years. During these eight years, I saw many people who started their careers with great passions but were quick to take shortcuts, withdraw from what they did or quit their jobs. These observations made me interested in both people's capacities and the social institutions that shape our lives.

As I reflect upon my life experiences, I recall that I have been always interested in acquiring new knowledge. My parents have strong work ethics and value education. They were 
always pushing me and my brother to do better in school because they wanted us to do better than they could do in their lives. Besides attending school, we were taking, at different times, English classes, piano classes, ballet classes, and even target-shooting classes.

When in Poland, I tutored students who came with different levels of academic proficiency but had very supporting parents who wanted their children to succeed. I quickly learned that students, even those of the same age, might have very different capacities. I recall that individualized lessons designed around topics of students' interests were the most engaging and effective. This approach provided a strong foundation for building a respectful relationship that created a safe environment for learning.

In 2016, I volunteered as a math mentor at two public elementary schools in Illinois. While the schools were located in the same town and within close proximity to each other, they differed in a number of ways. In one school, I was helping students who had problems with mathematical operations. I worked outside the classroom, in the school hallway with a different group of students switching groups every 15 minutes. Students were at very different levels of math proficiency but engaged well in practices involving some type of competition. In the other school, I assisted students who had problems with math in general. I worked with the struggling students at the table in the classroom while other students worked together at other tables. We worked out the problems from their math textbook that had to be completed each day as new concepts were introduced on the following day.

These tutoring and mentoring experiences not only gave me an opportunity to help students succeed, but allowed me to witness the complexity of student's learning first hand. It is not only student's capacities that set them for success or failure. As I witnessed during these 
experiences, pedagogical models, teachers, peers, and physical spaces greatly impact students' learning.

In terms of my exposure to Montessori philosophy, I initially learned about it through a friend who was an exchange student and lived with an American host family whose children attended a private Montessori school. Later on, I learned that one of my husband's college friends was a Montessori teacher and her son attended the school at which she taught. I had a few opportunities to see a Montessori classroom and was invited to the Montessori open days during which students demonstrated lessons. I was impressed by the way the Montessori classroom was organized and how independently these students navigated them. I started to read about Montessori method and attended the Seton Montessori Institute Paraprofessional Course that focused on Montessori philosophy and practice. This is when I learned about the importance of the "simplicity of the prepared environment", the role of adults in a child's life, the adult and child's power of observations, education for life, peace and positive change, and Montessori philosophy emphasis on developing and practicing skills such as ability to focus, share, and overcome obstacles.

As an honors undergraduate student, I also conducted my research involving students’ behavioral engagement and development of transferable skills (Franczak 2016). In my research, I inquired whether different types of elementary schools (conventional school, public Montessori school, and private Montessori school) foster a higher level of students' behavioral engagement and whether the elementary schools that foster higher levels of behavioral engagement also provide for a greater development of transferable skills. I followed a triangulation research model which involved collecting data through observations, surveys, and specifically designed forms and assessments. Through my analysis of On/Off task assessment, non-academic 
engagement, and the answers to teachers' surveys, I found a significant difference between students' levels of engagement and transferable skills across these three schools confirming my research inquiry. Conducting this study not only enhance my research skills but provided me with another opportunity to see implementation of Montessori method first hand.

My experiences in the legal field as well as a tutor, a Math mentor, and a Montessori researcher led me to interesting questions exploring a satisfactory life, learning processes, as well as the role of social institutions in shaping quality of our life. I believe that my life experiences, passion for knowledge, and a personal quest to improve quality of life for those at risk have prepared me well to conduct the proposed research.

\section{DEFINITIONS OF TERMS}

Academic Achievement - academic performance in Math and ELA (English/Language/ Arts) as measured by standardized tests.

School Effectiveness - school performance as captured by a combination of students' social skills and performance on standardized tests.

Conventional High Income School - school that follows a conventional program as prescribed by the Illinois State Board of Education with majority White students and a low percentage of students eligible for free or reduced lunch.

Conventional Low Income School - school that follows a conventional program as prescribed by the Illinois State Board of Education with majority of African-American and Hispanic students and a high percentage of students eligible for free or reduced lunch.

Conventional School - a school that follows a conventional program as prescribed by the Illinois State Board of Education. 
Montessori High Income School - a school that follows Montessori program with majority White students and a low percentage of students eligible for free or reduced lunch.

Montessori Low Income School - a school that follows Montessori program with majority

African American and Hispanic students and a high percentage of students eligible for free or reduced lunch.

Montessori School - a school that follows a Montessori method including mixed ages

classrooms, using Montessori materials, and having teachers trained in Montessori method and certified by the American Montessori Society (AMS).

Social Competence- set of skills necessary to get along and act positively within a group. For the purpose of this study, these skills include cooperation, responsibility and self-control as measured by the 5 Essentials Surveys completed by teachers. 


\section{CHAPTER II: REVIEW OF LITERATURE}

\section{EDUCATIONAL SYSTEM IN THE UNITED STATES}

\section{History}

The American education system is a two hundred year social project designed to fulfill the promise of the founding fathers who declared that all men are created equal. However, it wasn't until the Common School movement of 1840-1850 that elementary education in the U.S. was established as public and virtually free (Bennett deMarrais and LeCompte 1995).

The Common School movement proclaimed that "education, beyond all other devices of human origin, is a great equalizer of the conditions of men" (Putnam 2015:160). Horace Mann, the founder of the Common School movement, a secretary of the State Board of Education, and a prominent educational reformer of the nineteenth century believed that all children should have access to free education in public schools. He envisioned these public schools to form

a Free school system (that) knows no distinction of rich and poor, of bond and free, or between those who, in the imperfect light of this world, are seeking through different avenues, to reach the gate of heaven. Without money and without price, it throws open its doors, and spreads the table of its bounty, for all the children of the state (Bowles and Gintis 1976:167).

A growing nation increased numbers of students attending public schools but expansion of the industrial capitalist system and changes in labor laws led to changes in the role of the educational system (Bowles and Gintis 1976). In the spirit of the industrial revolution's emphasis on efficiency, the operation of schools started to diverge from Mann's original intentions of education as a great equalizer (Mann 1848). The new factory model of public school was inspired by Frederick Taylor's theories on management of factory employees (Bennett deMarrais and LeCompte 1995). Beginning in 1900, educational reformers argued that schools should be treated as factories that were transforming raw material (children) into products (adults). The 
operation of schools was guided by business practices and management protocols similar to the ones used to run efficient factories. Standardization was achieved through controlled tasks and detailed instructions while the worker (teacher) and the material (students) were disregarded in the process (Bowles and Gintis 1976). In contrast to the first public schools, students were now assigned to grades based on their age, the school day was divided into 32 minute periods, and curriculum reflected utilitarian values rather intelectual skills (Bowles and Gintis 1976).

The history of the American educational system demonstrates that the role and organization of education evolve along with socio-economic changes. During the era from 1766 to 1850 public schools were conceptualized as a great equalizer of the conditions of men. During the Industrial Revolution (1850-1914) schools adopted a factory model that focused on efficient production, operated under "scientific management principles" and provided limited social mobility (Bowles and Gintis 1976).

\section{Crisis in Education}

In the 1960s, James Coleman conducted one of the largest studies including 600,000 students, 60,000 teachers, and 4,000 public schools to assess the educational performance of minority students in the USA (Coleman 1966). His study revealed that minority students, with the exception of Asian Americans, performed lower than white students. In terms of achievement test scores students from different linguistic cultures (eg. Mexican-Americans), they did poorly in reading comprehension and verbal ability. Black students not only did poorly in reading comprehension and verbal ability but also in mathematics achievement and other five general areas (Coleman 1966).

Upon examination, Coleman observed that the composition of the student body in schools greatly impacted students' academic performance. He theorized that 'attributes of other 
students account for far more variation in the achievement of minority children than do any attributes of school facilities and slightly more than do attributes of staff" (Coleman 1966:302). He observed that minority students come to schools with serious educational deficiencies that are a result of numerous factors including but not limited to minority parents' disadvantageous socioeconomic status, their lack of education, and experiencing poverty. He concluded that lower academic performance of minority students was a result of segregated schools that kept students of different races, family socioeconomic and educational backgrounds separate (Coleman 1966). After the landmark court cases of Brown v. Board of Education in (1954), San Antonio Independent School District v. Rodriquz (1973), Millken v. Bradley (1974) and the Equal Educational Opportunity Act (1974) we tried to address some of the inequalities in our educational system. Brown (1954) and the Equal Educational Opportunity Act (1974) found that segregated education was unconstitutional and schools had a legal obligation to assure that students couldn't be discriminated against in their access to schools based on their race, ethnicity or gender (Coleman 1966). The success of Brown (1954), the Equal Educational Opportunity Act (1974), and policy programs such as Lyndon Johnson's "War on Poverty" have narrowed the achievement and inequality gap between white and black students (Bowles and Gintis 1976; Kozol 2005).

Despite early successes, schools with high racial segregation continued to have limited educational resources due to "less - qualified teachers, high levels of teacher turnover, and inadequate facilities and learning materials" (Rooks 2015:45). As a result of these pitfalls, students attending these schools have been more likely to receive lower grades, underperform on standardized tests, and dropping out of school (Kozol 2005; Rooks 2015). For instance, the 
studies from the early 1990s show that black and Hispanic students performed, on average, five years below the level of proficiency compared to white students (Kozol 2005).

More recent studies reveal a class gap in math and reading scores of K-12 students. Sean Reardon, a Stanford sociologist, found that "the achievement gap between children from highand low-income families is roughly 30-40 percent larger among children born in 2001 than among those born twenty-five years earlier" (Putnam 2015:161). This class gap is greater within the same racial groups than it is between racial groups. For students entering kindergarten, the class gap is two to three times greater than it is for the racial gap. Researchers, however, point out that schools do not create the opportunity gap. The gap exists before students enter kindergarten. They conclude that "schooling - unequal as it is in America - plays only a minor role in alleviating or creating test score gaps" (Putnam 2015:162). Overall, these studies show that the educational system in the USA is unequal and students' ascribed characteristics such as race, ethnicity, and parents' socioeconomic status greatly impact their educational success.

\section{Reasons Behind the Crisis}

There are a number of reasons why our public educational system has been unsuccessful in narrowing inequality gaps. Most researchers believe the reasons are residential segregation and unequal school funding system (Bowles and Gintis 1976; Kozol 2005; Putnam 2015).

Since the 1970s, we have witnessed increasing class-based residential segregation that perpetuates de facto class-based school segregation by placing high-income and low-income students into separate schools (Putnam 2015). Current level of school segregation is very similar to the levels we saw in 1960s with "60-80percentof districts major metropolitan have schools that are overwhelmingly segregated by race and economic level” (Rooks 2015:20). Studies show that a segregated inner-city school is more likely to have concentrated poverty levels than a 
school with an overwhelmingly white population (Kozol 2005). For instance, in 2001, Chicago public schools were 87 percent black and Hispanic. Half of the students in predominately black and Hispanic schools were poor and qualified for free or reduced lunch in contrast to 15 percent of those in white schools (Kozol 2005). Currently, public schools in Chicago are attended by 37 percent black and 46.8 percent of Hispanic students (Chicago Public Schools [CPS] 2017). Almost 78 percent of students in Chicago public schools come from economically disadvantaged families (CPS 2017).

In regards to school financing, public schools in the United States are funded by the government and depend largely on local property taxes. Therefore, affluent areas have more funds available to provide their schools with better resources to hire more qualified teachers and offer better programs (Putnam 2015). According to the Education Trust report that reviews trends of education finance, "in 31 states, districts with the highest percentage of minority children receive less funding per pupil than do districts with the fewest minority children" (Kozol 2005:245). Other studies that examine school performance and control for variables such as spending per pupil, teacher's experience and education also show disparities among poor and better off students (Putnam 2015). They conclude that it is a class-based residential segregation that is a significant predictor in the growing gap in performance between low and high-income schools (Putnam 2015).

Responses to the Crisis

The widening gap in school performance seen since the 1990s along with the neoliberal critique of public education as "insufficient in producing skilled, adaptable, and flexible labor force" (Apple 2003:23) have led to creation of a number of educational policies ("America 2000", "No Child Left Behind", "Race to the Top") ostensibly designed to improve student 
academic performance. In 2001, President George W. Bush announced a new program called "No Child Left Behind" requiring states to test and report students' academic skills in order for the schools to receive federal funding (Kozol 2005). Under this policy, all students are required to possess particular skills and knowledge by specific ages (grades) and their performance is measured by standardized tests (Martin 2004). Since schools that don't meet the standardized goals lose the federal funds, there is a significant emphasis on preparing students to do well on the standardized tests.

The "Race to the Top" was another government initiative introduced in 2009 during Barack Obama's presidency. The initiative was designed to improve American public education by making federal funds available to those who meet the scoring criteria but it created yet another competition between states schools (Celestin 2011). Specifically, under this initiative, schools earn points in a variety of categories including but not limited to "great teachers and leaders", "closing achievement gap", or "successful implementation of STEM in school curriculum" (Celestin 2011). Schools that already have good resources are in a better position to score high and receive additional funds since they can use existing resources to hire better teachers or offer better programs. Schools that have limited resources start at a disadvantage and are less successful in meeting criteria to qualify for funds. Such competition for funds further reinforces disparities between schools.

\section{MONTESSORI APPROACH}

\section{Overview of the Method}

In contrast to conventional educational models, Montessori method promotes collaboration over competition, emphasizes interactions in the process of developing academic and social skills but doesn't utilize tests (Lillard 2012). Students in Montessori programs are 
divided into three year age groups $(3-6,6-9,9-12)$ so they can learn from older students and guide younger students. The school curriculum provides students who are at least 4 years old with 3 hour blocks of uninterrupted time so they can work on their assignments. They also choose freely the learning activities within available curricular areas (eg. Sensorial Language, Practical Life) and use specifically designed educational materials (such as Colored Cylinders or Binomial Cube) (Lillard 2012).

This educational model is derived from Dr. Maria Montessori's pedagogical philosophy influenced by works of Jean-Marc Itard, Eduard Seguin, and Jean Piaget (Lillard 2012). Dr. Montessori was an Italian biologist, physician, educator, and women rights activist who initially worked in psychiatric clinics. As a part of her medical training, she became interested in helping mentally handicapped children. Her work received international attention when the mentally handicapped children she worked with passed the state educational tests (Lillard 2012).

While her accomplishments were celebrated, Dr. Montessori was more interested in learning why children without mental impairments did not do better on those tests. She then worked with Italian orphanages and later with children who came from poor families. She observed that we can provide students with learning opportunities that foster social, emotional, and cognitive growth if we recognize and address their individual development (Jacobson 2007). She identified four stages of child development (infancy 0-6, childhood 6-12, adolescence 12-18, and maturity 18-24) that correlate with different levels of movement, language, sensory perceptions and sense of order. She emphasized the importance of identifying each student's level of development in order to provide them with tasks that are challenging and attainable with their skills. 


\section{History}

In 1907, Dr. Montessori opened her first children's house (Casa dei Bambini) in one of Rome's poor neighborhoods (Lillard 2008). In 1915, she presented her educational approach at the Panama-Pacific International Exposition and was awarded the gold medal for education. Despite early success, her pedagogical approach, at times, was challenged by other educators such as William Kilpatrick who claimed that her ideas were neither new nor effective. Despite the criticism, she continued to work with students in Italy as well as in India, Netherlands, and the USA. Her goal was to better understand students and learning processes to create educational environments that cultivate students' fullest potential (Helfrich 2011). As a survivor of two wars, she believed "that the only way to change society was through the education of the young children” (Helfrich 2011:12).

In the USA, Montessori's educational approach was not popular until the 1960 s as it became a part of the magnet school movement whose goals were to reduce school segregation and address educational inequity (Jacobson 2007). Currently, there are 20,000 Montessori schools in the world and 4,500 are in the USA (NAMTA 2017). Among those 4,500 Montessori schools in the USA, 439 schools are public. While the majority of Montessori schools are private, an interest in bringing Montessori methods to public schooling increased in the 1980s in an attempt to create more diverse classrooms (Jacobson 2007). In the state of Illinois, there are thirty Montessori schools but only nine schools are public (US Montessori Census 2017). Out of nine public Montessori schools in Illinois, six schools are located in Chicago area. The other three public Montessori in Illinois schools are located in Decatur, Kankakee, and Rockford. Studies, in general, show that Montessori schools are successful in providing students with a 
high quality education as well as positive academic and socio-behavioral outcomes (Ervin et al. 2010; Karnes et al.1983; Lillard 2012).

While there is a substantial body of research addressing learning experiences in Montessori schools, there is limited work that compares public Montessori schools to conventional public elementary schools. I undertook the present work to expand our understanding of academic performance and social competence of students attending conventional and Montessori schools with similar demographic characteristics.

\section{Studies on Effectiveness of Montessori Model in Public School}

For this project, I reviewed studies exploring academic outcomes in math, reading, literacy, and social sciences in Montessori schools. I identified twenty four studies, conducted from 1970 (Stodolsky) through 2016 (Brown) that involve elementary students attending public Montessori programs.

In twenty-four studies comparing academic performance of students from conventional public and Montessori schools ${ }^{1}$, conclusions are mixed. Nine studies showed Montessori students outperformed students attending conventional schools in math and reading (Erwin et al. 2010; Karnes et al. 1983; Miller and Bizzell 1984; Moody and Riga 2011; Peng 2009). Twelve studies found "mixed outcomes" with Montessori students outperforming in some areas but not others (Brown 2016; Dohrmann, Rindskopf, Nishida, Gartner, Lipsky, and Grimm 2007; Fero 2007; Lillard and Este- Quest 2006; Mallet and Schroeder 2015). Four studies showed "no differences" with Montessori students performing at the same level as conventional students (Cisneros 1994; Salazar 2014; Sciarra and Dorsey 1976; Stodolsky 1970).

Within these twenty four studies, the longitudinal studies showed that students who were exposed to Montessori preschool experienced positive academic outcomes. These outcomes

\footnotetext{
${ }^{1}$ For a list of all these studies, please see Appendix A.
} 
however were not observed until later grades in elementary school, high school or college (Erwin et al. 2010; Dorhmann et al. 2007; Shankland, Genolini, Guelfi, and Ionescu 2010). Some studies also noted that the Montessori approach might be especially beneficial to low-income minority students (Brown 2016; Stodolsky 1970). In addition, some cross-sectional studies reveal positive academic outcomes for students attending Montessori programs while other studies found mixed outcomes or no differences (Brown 2016; Mallet and Schroeder 2015; McDurham 2011; Moody and Riga 2011; Peng 2009).

There is widespread agreement among researchers that human beings are social creatures and our interactions take place in a social context (Durlak, et al. 2011; Frey and Bos 2012). A good education should provide students, at their earliest ages, with formal knowledge and skills that can carry them on through their lives. The hope is that when they grow up, they become responsible and engaged global citizens who have a strong and positive sense of being a part of a larger society (Child Trends 2014).

While studying social competence has a long history, researchers are yet to agree on a definition and instruments that adequately measure it. The classic and most frequently used definition of social competence comes from Rose-Krasnor and refers to "the ability to achieve personal goals in social interaction while simultaneously maintaining positive relationships with others over time and across situations" (1997:113).

Over the years, this definition has been altered by different researchers to fit their scientific quest. For the purpose of my research, I am borrowing a more contemporary definition of social competence as used by the nation's largest nonprofit research organization, Child Trends. In their conceptualization, social competence encompasses a broad set of skills necessary to get along and act positively within a group. Those skills include a student's ability to take on 
others' perspectives, cooperate with peers to accomplish assigned tasks, positively resolve problems, and act according to social norms (Child Trends 2014).

I identified fifteen studies on social competence relevant to my research inquiry plus one study on social skills. ${ }^{2}$ Twelve of these studies examine academic performance and social competence, while three studies focus just on social competence. All fifteen studies were conducted between 1991 (Wentzel) and 2016 (Magelinskaite et al.) and only three involved Montessori students (Diekmann, Marius, and Gruehn 2013; Kayioi, Gokhan, and Kuúcu 2012; Lillard and Else-Quest2006).

Finally, research reveals that both academic achievement and social competence are important for students' success not only in school but in their lives (Putnam 2015). Successful students are those who are more likely to graduate high school, pursue higher education, engage in non-deviant activities, experience better health, and have more fulfilling personal and professional life (Putnam 2015). Therefore, the examination of social competence and its link with academic performance can broaden our understanding of the interplay of these two concepts and the importance of fostering both.

\section{THEORETICAL FRAMEWORK}

Scholars, across different disciplines, try to understand and explain the structures and processes guiding students' educational experiences. Within the discipline of sociology, it has been well established that the opportunities to succeed are greatly impacted by our ascribed and achieved characteristics. Ascribed attributes include socioeconomic family background, race, ethnicity, or gender and are basically characteristics we are born into. In contrast, achieved attributes such as education or occupation are the characteristics we gain as we move on with life (Blau and Duncan 1967).

\footnotetext{
${ }^{2}$ For the list of these studies, please refer to Appendix B.
} 
Modern sociological theories not only provide a framework for understanding the variation in student performance but are especially well suited for exploring fully the role of social class, race and ethnicity in shaping this performance. These modern theories include but are not limited to the theory of status attainment (Blau and Duncan 1967), educational value (Mickelsen 1990), oppositional culture (Ogbu 1998, 2003), academic profiling and label (Ochoa 2013), de facto segregation (Kozol 1992, 2005), and social reproduction (Bourdieu 1973, 1977 , 1986).

\section{Status Attainment Theory: Blau and Duncan}

Blau and Duncan's status attainment theory has been used for the longest by a number of scholars to explain the gap in test scores. This theory assumes that father's educational and occupational attainments as well as other demographic factors such as family socioeconomic status, race, and ethnicity are important predictors of one's educational and occupational attainment (Blau and Duncan 1967).

In their work of African American and White groups, they observed that the African Americans' educational opportunities were limited compared to Whites' educational opportunities (Blau and Duncan 1967). Their data showed that "whites are much more likely than nonwhites to attain higher educational level" (Blau and Duncan 1967:208). Half of African Americans "in contrast to one-quarter of the native whites have only eight or fewer years of schooling” (Blau and Duncan 1967: 208). They also analyzed data on father's occupational status and observed that the occupational status of African American fathers was lower when compared to the occupational status of White fathers (Blau and Duncan 1967:209). They concluded that while education is an important structure fostering upward mobility, it "is not as effective a route up for nonwhites as it is for whites" (Blau and Duncan 1967:210). 
They also pointed out that the trajectories controlling the direction of an individual's status attainment are determined at birth and create a vicious circle (1967:204). In the case of African American students, they are already at a disadvantage when entering schools due parental insufficiencies (ex. parents limited education and occupational status) and when at school, they become handicapped even further (Blau and Duncan 1967).

Furstenberg and colleges (1999) expanded status attainment theory by observing that poor educational attainment of African American students was also positively correlated with the neighborhood resources available to them. Due to residential race segregation, most African American families are placed in less desirable neighborhoods. Those less desirable neighborhoods have limited school resources that simply cannot "adequately equip them with skills for higher education or for securing a good job" (Furstenberg, Cook, Eccles, Elder, Sameroff 1999:213). The disappearance of manufacturing and skilled jobs in the 70s and the 80s in the USA led to a "hypersegregation" of rich and poor neighborhoods and transformed poor neighborhoods into fields of crime, addiction, teenage pregnancies, gangs and limited support (Furstenberg et al.1999). They also pointed out a "disturbing trend" (Furstenberg et al.1992:212) that those who don't secure skills and sources at their early years are unlikely to improve their future situation. This is very apparent, especially, for black male and it was theorized that "the racial divide may become much wider" specifically for this group (Furstenberg et al.1999:213). They concluded that since student's failure and dropout rates are greater for students who attend disadvantageous neighborhood schools, African American youth is more prone to academic failure (Furstenberg et al.1999). 


\section{Educational Value Theory: Roslyn Mickelson}

This theory is based on students' beliefs associated with the educational system. Specifically, Mickelson (1990) implies that the difference in students' educational achievement can be explained through examination of students' abstract beliefs versus concrete beliefs. An abstract belief is presuming that getting good education will lead to a good job. A concrete belief considers the reality of getting a job. Under the abstract belief system, the dominant American attitudes towards education are regarded ideological and imply that "education is a solution to most of social problems" (Mickelson 1990:46). On the other hand, under the concrete belief system, American attitudes towards education are examined within the context of class, race, ethnicity and considers the impact these attributes have on academic attainment (Mickelson 1990). She continues that the abstract belief system is a part of ideology that views education as a core of everybody's success and therefore appears hopeful. In contrast, the concrete belief system is a part of material realities revealing that our social class, race, and ethnicity provide for variations of student's educational experiences and outcomes (Mickelson 1990).

According to Mickelson (1990), exploration of students' concrete beliefs is crucial for understanding students' academic performance. She conceptualizes that since concrete beliefs exist in students' material reality, they are best suited for addressing the impact they have on student's achievement (Mickelson 1990). She theorized that it was the opportunity structures (determined by class, race, ethnicity) that "shape students' concrete attitudes that reflect the relationship between perceived opportunity and academic performance“ (Mickelson 1990:59). Because working class students and minority students are exposed to parents, siblings, and neighbors whose real-world experiences do not reflect high returns on their investment in education, those working class students and minority students become more skeptical in 
believing that education provides for equal opportunity (Mickelson 1990). Since these students are less likely to believe in education as a structure providing for their success on the job market, they are less invested in their academic work that ultimately leads to lower academic performance (Mickelson 1990).

She theorized that no educational reforms will improve the educational experiences of these students unless we address the current opportunity structures (Mickelson 1990).

\section{Oppositional Culture Theory: John Ogbu}

This theory implies that minority students oppose school as a result of their aversion to the cultural standards of the group that oppressed them in the past (Ogbu 1998). In the context of the US, this theory implies that American minority groups oppose school and standards of white middle class students. Ogbu classifies minorities into two groups: voluntary and involuntary minorities. This classification of minority groups is essential for understanding the oppositional culture theory since the theory is rooted in group's history and culture and not race per se.

Specifically, voluntary minorities are immigrants who "moved to the United States because they expected better opportunities (better jobs, more political or religious freedom) than they had in their homelands." On the other hand, involuntary minorities, are nonimmigrant people who have been conquered, colonized, or enslaved and therefore incorporated against their will (Ogbu 1998:10). Involuntary minorities in the USA (African Americans, Native Americans) then recognize that their presence in the USA was forced on them by white men.

Since each minority group originated due to different casual factors, each of the minority develops a different cultural model (Ogbu 1998). Those cultural models become frameworks that allow us to understand the world around us and guide our actions. The cultural model can be explored in terms of frame of reference, folk theories of "making it" (and role models), degree of 
trust of white people and their institutions, and beliefs about effect of adopting white ways on minority identity.

Involuntary minorities (such as African Americans) have a dual frame of reference (Ogbu 1998). On one hand, they compare their socio-economic status to the population in the USA. On the other hand, they compare their socio-economic status to middle-class White Americans. They ultimately believe that white middle-class has more opportunities.

The folk theories of "making it" are people's beliefs rather some social norms that provide guides how we achieve our success. Since majority of African Americans continue to face employment and wage discrimination in a system that is controlled by Whites, they see that discrimination is institutionalized and education does not overcome the racism (Ogbu 1998). Involuntary minorities who have been experiencing a long history of oppression and subjugation, do not trust institutions such as schools because they traditionally have been controlled by dominant group. Finally, in contrast to voluntary minorities who come to the U.S. in search for a better life and willingly learn the language and the culture of the Whites, involuntary minorities were brought to the U.S. by force. They want to preserve their culture as it is a part of their collective identity and they feel that the success standards are forced on them by the dominant class.

Conceptualizing educational performance of minority students' in the framework of Ogbu's oppositional culture theory involves examination of two factors: treatment and mistreatment of minorities in the educational system as well as their responses to schools as a consequence of this treatment and mistreatment (Ogbu 1998). Again, in the context of American educational system, Ogbu specifically investigated the relationship between Whites towards African Americans and how this relationship impact African American students' educational 
performance (Ogbu 1998). Specifically, he noted that African American students experienced discriminatory treatment through educational policies and practices (school segregation, unequal school funding), in-school teacher-student relationships (ability grouping, expectations), and societal rewards they received for their school achievements (job opportunities, wages). Since the discriminatory treatment of African Americans in educational system is evident, it becomes a belief of African American minorities that the system is ultimately controlled by white middle class. As a response to this status quo, African American minority students oppose white middle class educational system and become disengaged from educational attainment. This opposition of white middle class system is reflected in African American minority students' disengagement in school work and cutting classes. He then suggests that lower academic performance of low income African American minorities is a result of their belief system that makes them inferior to the dominant white middle class who controls the educational system.

When comparing African American students from different social classes, Ogbu (2003) notes that in as much as we observe it among White students, those who come from higher social classes perform academically better than those who come from lower social classes. However, when comparing the middle class African American students to middle class White students, Ogbu points out that African American students perform lower to their White counterparts (2003). He also notes that the attitudes and views about academic success of middle class and working class African Americans appear similar. Student from both classes exhibited greater disengagement and blame teachers for their performance.

In as much as working class students didn't receive too much help from their parents who had to work two jobs to pay the bills, the middle class parents didn't have time to help out as they also had to work more or longer hours to maintain their middle class status (Ogbu 2003). 
However, Ogbu noted that middle class children could be prepared better for school because of their early school education and therefore didn't need full parental guidance (2003). Theory of Profiling and Labeling: Glida Ochoa

Glida Ochoa explains the academic performance gap between Latino minority students and Asian American as well as white students through her theory of students' profiling and labeling. She notes that Asian-Americans have a higher-than-average educational backgrounds and incomes that ultimately provide their children with greater educational resources (Ochoa 2013). In California, where she conducted her study, sixty percents of students who were Hispanic came from socioeconomically disadvantageous families.

While attention is paid to standardized tests as the primary measurement of achievement, Ochoa (2013) notes that we disregard other factors such as the construction of the test, school social inequalities, students' background as well as their skills and experiences that greatly impact students' test performance. She also theorized that by reporting the scores of the standardized tests by race and ethnicity, we introduce labels and stereotypes that regard students' performance as a result of their biological attributes rather than being socially constructed.

Her theory of profiling implies that school officials' expectations and treatment of students differ by students' ascribed attributes such as but not limited to class, race and ethnicity. This profiling not only teaches students about their place in school but also in society. Before students start getting ready for the standardized tests, teachers place their students in different programs. The placement is based on teachers' perceptions of their students and those placements become less advantageous for some students than they are for others. She notes that our education system "sorts, divides, and treats students disparately, fueling their separation and the feeling of being different and unequal" (Ochoa 2013:57). 
Students who are placed in the high track programs are offered high status knowledge that provides greater opportunities to develop skills such as "critical thinking, analytical capabilities, and public speaking" that ultimately prepares them better for entrance in college (Ochoa 2013:69). But she explains that it is not only placing students in different programs that allows some students to grow and others to fail but that placing students in those different programs starts a chain reaction that perpetuate the cycle of inequality. High-rank students, who mostly come from a middle or high class have an easy access to counselor in contrast to low rank students who usually come from working class. As this elitism of high rank students becomes more evident, the low rank students become more resilient.

She theorized that labeling students based on their class, race and ethnicity as high performers or low performers reinforces a "cycle of privilege" (Ochoa 2013). The "model minority" label pressures Asian American students to over perform while labels associated with the academic inferiority assigned to working class Hispanic students force them to "internalize others' low expectations of them and underperform" (Ochoa 2013:222).

Like other theorists, she points out that regardless of race and ethnicity, students who come from lower classes perform on the bottom of the academic hierarchy while students who come from higher classes perform at the top (Ochoa 2013). Based on students' reflections, she concluded that increasing the percentage of teachers of different backgrounds might improve learning experiences and academic performance of students who traditionally might be set for a failure.

\section{De Facto Segregation: Jonathan Kozol}

Jonathan Kozol investigation of public education in the USA not only resulted in publishing a number of books devoted to this matter but also make him one of the most 
controversial educational reformers in the USA. His theory of the De Facto Segregation is based on his observations of students attending public schools in 30 neighborhoods in East St.Louis, Chicago, New York City, Cincinnati, and Washington D.C between 1988-1990 (Kozol 1992) as well as schools in 6 other states between 2000 and 2005 (Kozol 2005).

Even though Kozol visited schools initially some 37 years after the Supreme Court decision in Brown v Board of Education (1954) finding segregated education was unconstitutional, he observed "the remarkable degree of segregation that persisted almost everywhere" (Kozol 1992:2). He noted that the schools he visited were between 95-99 percent non-white and poor. He observed that " a segregated inner-city school is almost six times as likely to be a school of concentrated poverty as is a school that has an overwhelmingly white population" (Kozol 2005:20).

Public schools in the USA are funded by the government and depend on the property taxes. Kozol (1992) explains that this practice is problematic because wealthy districts generate greater property taxes that provide for greater funds for their schools while poor districts generate lesser revenues that provide limited funds for their schools. In contrast to poor school districts, schools in wealthier districts then can afford smaller classrooms, additional school resources or better salaries for the teachers that all ultimately provide for a greater performance of their students (Kozol 1992, 2005). He concludes that relying on property taxes reinforces inequality within our school system that ultimately reflects de facto segregation of our society (Kozol 1992; Kozol 2005).

He notes that the Education Trust confirms that we know about funding gap and its unfairness. While this gap, thanks to steady decrease of school segregation, "narrowed for three 
decades up until the late years of the 1980s, (it) started to widen once more in the early 1990s" (Kozol 2005:280).

Finally, he theorized based on reflections of students, educators, and community members that "going to school with all the races is more important than a modern school" (Kozol 1992: 31). Unfortunately, there is a little integration even at schools that are attended by White and Asian students (Kozol 1992). He also recommended placing people of color in charge of our cities, welfare system, or public schools domains not only "protects the white society against the charges of racism" (Kozol 1992:195) but provides enforcement "since a black official is expected to be (...) more severe in putting down unrest" (Kozol 1992:195).

\section{Social Reproduction: Pierre Bourdieu}

Social reproduction is the classic theory investigating the relationship between students' demographics and their academic performance. The theory is associated with Pierre Bourdieu who argued that educational system not only represents the interest of the dominant class but contributes to the reproduction of the structure of the class relationships by engaging in unequal distribution of cultural capital (Bourdieu and Passeron 1977). While the mainstream narrative considers academic performance as a result of natural abilities, Bourdieu argues that it is unequal distribution of cultural capital that leads to differences in academic performance among students from different socioeconomic backgrounds (Bourdieu and Passeron 1986).

He defines cultural capital as cultural competence closely related to one's social position, institutionalized in the form of educational qualifications that can be convertible into economic capital (Bourdieu and Passeron 1986). Bourdieu observed that "those which are richest in cultural capital are more inclined to invest in their children's education, cultural practices liable to maintain and increase their specific rarity" that ultimately reinforces their advantage (1973: 
64). He continued that while home-school relations and home based experiences of these families from higher social classes align more closely with the values of educational institutions, the possession of social and cultural capital also becomes advantageous in the field of domination and subordination that is depended on the amount of capital (Bourdieu 1973).

Bourdieu pointed out that the dominant class is able to secure this monopoly of its cultures as it owns instruments of appropriation (eg. education). While education system, ostensibly, appears autonomous and independent, it is depended on class relation (Bourdieu and Passeron 1977). For one, the role of educational system has been " the conservation of culture inherited from the past" by selecting and training individuals in the established manner to maintain social order (Bourdieu and Passeron 1977:18). Therefore, social reproduction and the disparities in academic performance among students who come from different social backgrounds will continue as long as the educational system fulfills its main role and masks the interest of the dominant class (Bourdieu and Passeron 1977).

Scholars discussed in this section provide theories exploring specific structures and processes shaping students' educational experiences. They all also recognized that there are a number of different factors contributing to variation in academic performance among students who differ in their social class, race and ethnicity. While Blau and Duncan (1967) theorized that it was the family background (specifically father's occupational status) that greatly contributed to the consistent differences in students' academic performance, Mickelson (1990) provided that, regardless of students' family background, all students believed in the importance of education. It is also evident that due to lack of primary education or parental capital of low income and minority students enter schools at disadvantages that then due to school structures and processes 
set them even further apart from the other students (Blau and Duncan 1967; Ochoa 2013, Bourdieu and Passeron 1977,1986).

Another interesting parallel among some of these theorists is their focus on importance of conceptualization of one's surroundings and its impact on students' academic performance. Furstenberg (1998) theorized that living in poor neighborhoods doesn't provide resources or support for growth. Mickelson (1990) pointed out that because working class racial minorities are surrounded by people who do not receive a good return on their educational investment, they do not believe education will improve their quality of life. Kozol (1992, 2005) based on students' reflections theorized that students felt that the government didn't care about them when it did not provide funds to their schools. Ochoa (2013) pointed out that working class Hispanic students internalize the labels associated with their academic inferiority that leads to their underperformance.

To conclude, while I discussed only a handful of scholars who examined the structures and process guiding students' academic performance, they are fine examples of theorists who work out of the sociological paradigm. Blau and Duncan's theory of status attainment (1967), Ogbu's theory of oppositional cultural theory (1998, 2004), Mickelson's educational value theory (1990), Ochoa's theory of profiling and label (2013), Kozol's de facto segregation theory (1992, 2005), and Bourdieu's social reproduction theory offer compelling explanations that can provide for our understanding of the complexity of social class, race, and education. While studies show that low income and minorities groups underperform academically, sociological theories point out that this is further reinforced by current educational policies and practices (segregation, labeling, funding, and profiling) that disadvantage these students and set them for a failure. 
Within theoretical context, the hope of this study is to determine whether an alternative educational model such as Montessori method can actually begin to dismantle some of these structural obstacles and lead to more equal educational experiences. If not, I hope this work at least offers theoretical foundations that can become starting points of our discussions involving changes that will improve educational experiences of students with different demographics. 


\section{CHAPTER III: METHODOLOGY}

The purpose of this study was to explore academic performance and social competencies in Montessori and conventional schools of students in elementary grades. This was a comparative case study involving two Montessori and two conventional public schools in the Chicago Public School district.

\section{DATA}

I relied on student academic data, lunch-eligibility data, and student demographics gathered in the Illinois Report Cards and student social competence data gathered in the 5Essentials Survey Reports.

\section{Data Strengths}

In terms of strengths, this secondary data provided a large statistical source that was representative of the studied population (students attending four schools in my sample). Using these data not only saved time but also reduced the cost of the study. Furthermore, using aggregated data was helpful to identify common characteristics of the studied population and preserved the privacy of the individuals included in the sample. In addition, the original data were collected by a state educational agency which increases the credibility of the data quality. POPULATION AND PROCEDURES

To increase the validity of my comparisons, I limited this study to a single school district in Chicago. Examining school performance within one city and one school district allowed me to reduce the impact of disparate school resources (eg. instructional and operating spending per student) on the effectiveness of educational models explored in this study. According to the US Montessori Census (2018), there are nine public schools in Illinois that offer Montessori school 
programs. Out of those nine schools, six serve students in Chicago school district 299, and two of them offer only Montessori program.

Since my study compared Montessori to conventional schools, I employed a purposive sample to identify two Montessori and two conventional schools. I decided to employ a purposive sample since it allowed me to select schools with similar demographics but different educational approaches. Controlling for school demographics allowed for reducing the effect demographics have on school performance or the effectiveness of educational approaches.

The first public Montessori school (MHI) and conventional school (CHI) consisted of students who came from more advantageous social backgrounds compared to students in the other public Montessori school (MLI) and conventional school (CLI). Social background was determined by the overall percentage of school eligibility for free or reduced price lunch as well as overall school racial/ethnic composition.

To select two Montessori schools for my study, I first identified public elementary Montessori schools located in Chicago, Illinois using the USA Montessori Census directory. Next, I examined the Illinois Report Cards for these schools to assess their racial/ethnic composition and the percentage of student who qualify for a free or reduced lunch. I selected one school that had a student population with more advantageous demographics and one school with a student population with less advantageous demographics. A school with majority white students and a low percentage of students eligible for free or reduced lunch was considered more advantageous and coded as "Montessori high income school" (MHI). A school with majority African American and Hispanic students and a high percentage of students eligible for free or reduced lunch was considered less advantageous and coded as "Montessori low income school" (MLI). 
The two Montessori schools I selected for the study are public magnet schools that offer only Montessori programs. As defined by the CPS (2018), a magnet school "specializes in subject areas, such as math and science, fine arts, world language, or humanities." There are no attendance boundaries and magnet schools accept students throughout the city. To enroll in these schools, students have to file an application and are selected by a computerized lottery conducted by the CPS (2018).

Based on the materials available on the schools website, the two Montessori schools were located in the same schools district in Chicago and offered early childhood, elementary I (ages 69 or $1^{\text {st }}$ through $3^{\text {rd }}$ grades), elementary II (ages $9-12$ or $4^{\text {th }}$ grade through $6^{\text {th }}$ grades), and middle school programs (ages 12-14 or $7^{\text {th }}$ through $8^{\text {th }}$ grades). They were accredited by the American Montessori Society (AMS) and the guidelines for the accreditation can be found at https://amshq.org/School-Resources/AMS-School-Accreditation. Since these two Montessori schools were public, they were accountable for addressing the Common Core State Standards. Students attending these schools took standardized tests and teachers were certified by the State of Illinois. Therefore, the implementation of the classic Montessori fidelity in these two schools was reduced. However, aligned with the Montessori model, these two schools offered mixed ages classrooms, used Montessori materials, and teachers were trained in Montessori method and certified by the AMS.

Once, I selected the Montessori schools, I identified two conventional schools (CHI, CLI). I initially generated a list of conventional public schools within close proximity to the two selected Montessori schools using a search engine called Public School Review. This search engine provided profiles of public schools in the USA. Once on the site, I was prompted to provide the name or location of the school, a distance from the school, grade level (s), and type 
of school (ex. magnet, charter, no preference). I searched for public elementary schools within 5 miles from the two public Montessori schools. The results provided a list of the schools that matched the searching criteria. I cross checked the names of these schools with the CPS Index of elementary schools, examined the Illinois Report Cards for these schools to assess their racial/ethnic composition and the percentage of students who qualified for a free or reduced lunch, and reviewed their websites to assure that they fit a conventional model. My goal was to identify two conventional public schools in the same school district that had similar demographics and socioeconomic profiles when compared to the Montessori schools I had already selected for this study. This approach was designed to provide me with one low income and high income conventional public school. By controlling for the effect of school variables such as school resources and student variables such as their demographics, I was in a better position to assess the impact of Montessori and conventional educational approach on student performance.

Unfortunately, I was unsuccessful in my attempts to find conventional schools with demographics similar to Montessori schools that were located within 5 miles from each other. Upon a closer review, many schools in the southern part of this particular school district were closed and/or were attended by majority of Africa American students.

I expanded then the school geographical limitations set at the preliminary stages of the design. While keeping my search still within one city and one school district, I utilized the Free and Reduced-Price Meal Eligibility Data provided by the Illinois State Board of Education (2018), the CPS Elementary School Index, the Illinois Report Cards, and school websites to identify two conventional schools for my study. 
The Free and Reduced-Price Meal Eligibility Data were used to build a subset data of schools in this one district with the percentage of students in those schools eligible for a free/reduced-price meal. Next, I grouped schools with similar percentages of students eligible for a free/reduced-price meal on separate spreadsheets (1-29 percent, 30-39 percent, 40-49 percent, 50-59 percent, 60-79 percent, 80-100 percent). I then reviewed the group of schools that had a similar percentage of students eligible for a free/reduced-price meal to two public Montessori schools I selected for this study. Next, I cross checked the names of the schools with the CPS Elementary School Index to assure they were not magnet or charter schools. I also examined the Illinois Report Cards for these schools to assess their racial/ethnic composition and the percentage of student who qualify for a free or reduced lunch, and reviewed the school websites to assure that they fit a conventional model.

This approach allowed me to identify two conventional schools with the demographics similar to two Montessori schools that are located in the same school district. A closer review of schools in this district revealed that there are just few schools that are classic conventional and their demographics were very skewed. Most schools with demographics similar to Montessori schools in this district were magnet, magnet cluster, charter, gifted, or private. In addition, those few classic conventional schools were attended by minority students.

Ultimately, I identified two conventional schools that were located in the same district as the two Montessori schools. Based on the information available on the schools websites, the two conventional schools I selected for the study were public magnet-cluster schools. As defined by the CPS (2018), a magnet-cluster school "is a specialized neighborhood school" that "focuses their curriculum on one of four subject areas: fine and performing arts, world language, technology, or International Baccalaureate in Primary or Middle Years". These schools have the 
neighborhood attendance boundary so to enroll in these schools, students have to live in the neighborhood (CPS 2018).

The two conventional schools I selected for the study were a part of the world language magnet-cluster schools and offered, in addition to a regular curriculum, Spanish classes. Despite offering Spanish classes, they did not differ from a classic conventional model. These two conventional schools offered programs from pre-kindergarten through $8^{\text {th }}$ grade. Since these two schools were public, they were accountable for following and addressing the Common Core State Standards, students attending these schools took standardized tests, and teachers were certified by the State of Illinois. Aligned with a classic conventional model, students were matched by age and grade with a one year increment.

Since the schools selected for this study were considered public magnet (Montessori) and magnet-cluster schools (Conventional), I also reviewed data on school finances to assure none of them had access to a substantially greater financial help. Data on schools finances was released to the public by the CPS when announcing decreases in school funding for 2016-2017 school year (Berlin and Husain 2016). According to data, two high income schools selected for this study received fewer funds than two low income schools did. When consider the number of students attending each school, conventional schools received fewer funds per pupil when compared to Montessori schools.

According to the Illinois State Board of Education, currently, public does not have access to school-level financial data that include sources and amounts of funds these schools receive (ISBE 2018). Before any conclusions can be drawn between funding of these four schools and performance of students attending these schools, school-level financial data are needed to determine the revenue by sources (eg. federal funding versus local property taxes), expenditure 
by funds (eg. education versus debt services), and expenditure per pupil (instructional versus operational) (ISBE School Report Card). Starting in 2019, public schools will have to report these data on their School Report Cards and funding of the schools selected for this study could be examined further.

\section{SAMPLE}

The sample for this study included four public elementary schools (two Montessori and two conventional schools). Schools within the same school district were matched by the schools demographics including the percentage of students eligible for a free/reduced-price meal and student racial/ethnic composition. Demographics of schools selected for this study are displayed in Table 1 titled "School Characteristics in Percentages by School".

Table 1

School Characteristics in Percentages by School

\begin{tabular}{ccccc}
\hline Characteristics & $\begin{array}{c}\text { Montessori } \\
\text { Low Income }\end{array}$ & $\begin{array}{c}\text { Conventional } \\
\text { Low Income }\end{array}$ & $\begin{array}{c}\text { Montessori High } \\
\text { Income }\end{array}$ & $\begin{array}{c}\text { Conventional } \\
\text { High Income }\end{array}$ \\
\hline Size & 406 & 701 & 344 & 409 \\
Free/reduced lunch & 54.2 & 58.2 & 30.5 & 20.0 \\
White & 16.5 & 16.1 & 40.1 & 59.2 \\
African American & 61.1 & 63.1 & 6.1 & 1.5 \\
Hispanic & 12.0 & 8.4 & 38.1 & 30.6 \\
Asian & 5.2 & 6.1 & 4.9 & 5.1 \\
Other & 4.4 & 6.2 & 10.8 & 3.6 \\
\hline
\end{tabular}

\section{MEASURES}

To examine academic performance, I relied on data reported in the Illinois school report cards. In order to examine social competences of students attending these four schools, I relied on data reported in 5Essentials Survey Reports from all teachers in these four schools. 


\section{Illinois School Report Cards and Academic Performance}

In accordance with Title IX, the Illinois Report Cards are produced by all schools that receive government funding. These data are publicly available to use for families, researchers, and policy makers (Illinois Report Card 2017). The Illinois Report Cards provide aggregated data on students' demographics, performance, attendance, graduation rates, as well as teacher qualifications, and other information that are used to measure yearly progress (2017).

Aggregated data on academic performance derive from the scores on standardized tests for students in $3^{\text {rd }}$ through $8^{\text {th }}$ grades. The Illinois State Board of Education releases student raw test scores as student-level data and only with parental consent. The procedures for requesting student-level data from Chicago Public Schools require an application fee (\$50.00) and a lengthy review conducted by the Research Review Board that could take up to 90 days (CPS 2017). Even if my request for student raw test scores was approved, I could be unable to collect enough signed consents to secure sufficient data for analysis. Due to these time constraints, using aggregated data available on Illinois Report Cards was the most practical approach to complete my work.

\section{The 5Essential Survey Reports and Social Competence}

The State Boards of Education have recognized that test scores don't necessary capture all aspects of school learning and teaching (UChicago Consortium on School Research 2017). In 2011, the Illinois Senate passed a Bill 7 that has required all public schools to participate in a school climate and learning conditions survey called the 5Essentials Survey. The 5Essentials Survey is an evidence-based tool designed to improve schools. It was developed by the Illinois

State Board of Education in collaboration with The University of Chicago Consortium on School Research at the University of Chicago Urban Education Institute and Chicago Public Schools. 
The surveys are completed by all school teachers, $6^{\text {th }}$ through $8^{\text {th }}$ grade students and parents. Some survey results are provided on Illinois Report Cards. Complete aggregated results are featured in the 5Essentials Survey Reports available to public at https://illinois.5essentials.org/2016/s/ 070161620022009/. The 5Essentials Survey Reports provide data aggregated to school level on five non-academic variables that are predictive of school success. These variables include effective leaders, collaborative teachers, involved families, a supportive environment and ambitious instruction (UChicago Consortium on School Research 2017).

For the purpose of my research, I used aggregated data on social competence that derived from the answers to the 5Essentials Survey completed by classroom teachers. I contacted the University of Chicago Consortium on Chicago School Research, who possess the data, and inquired how I can request teacher survey data aggregated to the individual grade levels rather than the school level. Unfortunately, I was advised that neither the University of Chicago Consortium on School Research nor University of Chicago IMPACT has authorization to share teacher survey data as aggregated to the separate grade levels or range of grade levels, as this can breach respondent confidentiality. Due to these limitations, I used data aggregated to schoollevel as they are available in the 5Essentials Survey Reports.

\section{Academic Performance}

In order to examine student academic performance, I used the Report Card data that derive from the 2016 standardized tests scores in Math and ELA (English/Language/ Arts) for students from $3^{\text {rd }}$ through $6^{\text {th }}$ grade. Starting in 2015, data on student academic performance have been measured with the help of PARCC standardized tests (Partnership for Assessment of Readiness for College and Careers). According to ISBE (2017),

The Partnership for Assessment of Readiness for College and Career (PARCC) tests are designed to measure performance against rigorous 
standards. The tests go beyond multiple choice questions and require students to use skills like analyzing, problem solving, and writing effectively. All of these skills are necessary in order for students to be successful in the real world.

Student academic performance on school report cards reflects the percentage of students meeting state expectations for each grade. PARCC uses a 5 level scale to assess student achievement (ISBE 2017). Particular Performance Levels correspond with specific ranges of scores from 650 through 850 . Level 1 indicates the percentage of students who do not meet expectations; Level 2 indicates the percentage of students who partially meet expectations; Level 3 indicates the percentage of students approaching expectations; Level 4 indicates percentage of students meeting expectations; and Level 5 indicates percentage of students who exceed the expectations (ISBE 2017). Levels, ranges of points, and the interpretation of the levels are summarized in Table 2.

Table 2

PARCC Score and Levels

\begin{tabular}{ccc}
\hline Range of Points & Levels & Interpretation \\
\hline $650-699$ & 1 & Not meeting Expectations \\
$700-724$ & 2 & Partially meeting Expectations \\
$725-749$ & 3 & Approaching Expectations \\
$750-809$ & 4 & Meeting Expectations \\
$810-850$ & 5 & Exceed Expectations \\
\hline
\end{tabular}

Academic data in Report Cards are grouped by grade levels and display the percentages of students in each grade that performed at each level.

Initially PARCC tests were more complex than the standardized tests (ISAT) used for the past two decades (Adams 2015). Starting with 2015-2016 academic year, a new version of PARCC tests was utilized. The tests were shorter, included fewer questions, and were administered only once at the end of the school year (PARCC 2016). I decided to use the data for 
2016-2017 academic year as it was a second time the new version of PARCC was used and students in grade four, five, and six would be more familiar and therefore possibly more comfortable with completing this test instrument.

\section{Social Competence}

In order to examine student social competence, I used data provided in teachers' responses to the 5Essentials Survey conducted for 2016-2017 academic years. These surveys asked teachers to assess different statements. Statements included in the Ambitious Instruction and Supplemental sections of the survey appear to be most relevant to my research inquiry on social competence operationalized as cooperation, teamwork, and self-control. Table 3 provides a list of the categories, statements and available answers provided in the teacher survey.

Table 3

Teacher 5Essentials Survey

\begin{tabular}{|c|c|c|}
\hline $\begin{array}{c}\text { Category/ } \\
\text { Subcategory }\end{array}$ & Statement & Options \\
\hline $\begin{array}{l}\text { Ambitious Instruction / } \\
\text { Quality of Student } \\
\text { Discussion }\end{array}$ & $\begin{array}{l}\text { 1. Students provide constructive feedback } \\
\text { to their peers. } \\
\text { 2. Students interact with course material } \\
\text { and one another to build and apply critical } \\
\text { reading and writing skills. } \\
\text { 3. Students build on each other's ideas } \\
\text { during discussion. } \\
\text { 4. Students show each other respect. }\end{array}$ & $\begin{array}{l}\text { Never, Rarely, } \\
\text { Sometimes, } \\
\text { Almost always }\end{array}$ \\
\hline $\begin{array}{l}\text { Supplemental/ } \\
\text { Classroom Disruptions }\end{array}$ & $\begin{array}{l}\text { 1. Threaten you verbally. } \\
\text { 2. Create serious behavior problems in } \\
\text { your class. } \\
\text { 3. Refuse to respond when addressed. } \\
\text { 4. Use inappropriate language during class. }\end{array}$ & $\begin{array}{l}\text { None, A few, A } \\
\text { lot, Almost all }\end{array}$ \\
\hline $\begin{array}{l}\text { Supplemental/ } \\
\text { Responsibility }\end{array}$ & $\begin{array}{l}\text { 1. Always turn in their homework. } \\
\text { 2. Come to class prepared with the } \\
\text { appropriate supplies and books. } \\
\text { 3. Actively participate in class activities. } \\
\text { 4. Regularly pay attention in class. } \\
\text { 5. Come to class on time. } \\
\text { 6. Attend class regularly. }\end{array}$ & $\begin{array}{l}\text { None, Some, } \\
\text { About Half, Most, } \\
\text { Nearly all }\end{array}$ \\
\hline
\end{tabular}




\section{Case Measures}

\section{Academic performance}

A preliminary review of literature reveals that academic achievement is usually measured using standardized test scores (Brown 2016, Ervin et al. 2010, Mallet and Schroeder 2015). Since data from the Illinois Report Cards are provided by grade level, I combined the percentages of all grades by subjects (Math, ELA) to create a school-level data for each school in the study (MHI, MLI, CHI, CLI). This allowed me to compare the overall performance in the Montessori and conventional schools. School-level academic data were also used to analyze the relationship between academic performance and the social competence of students attending these four schools.

\section{Social competence}

Social competence was measured with data from the teacher assessments compiled in the 5Essetnials Survey Reports. Items from the survey were selected based on their ability to measure social skills such as cooperation, responsibility, and self-control.

Cooperation was assessed with the data from the assessments of following statements:

1. Students provide constructive feedback to their peers.

2. Students interact with course material and one another to build and apply critical reading and writing skills.

3. Students build on each other's ideas during discussion.

4. Students show each other respect.

Responsibility was assessed with the data from the assessments of following statements:

1. Students are active participants in their own learning.

2. Students regularly attend class. 
3. Students are regularly prepared to learn.

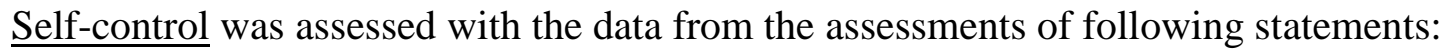

1. Students create serious behavioral problems.

2. Students use inappropriate language.

3. Students refused to respond when addressed.

I created a data subset that focused on statements relevant to the three social skills (cooperation, responsibility, and self-control) that I investigated in my study. As with academic performance, I compared public Montessori schools (MHI, MLI) to the public conventional schools (CHI, CLI) using school-level data for each competency. This approach allowed me to examine the level of these three social skills in schools with similar demographics but different educational approaches.

Data regarding social competence were also used to determine any links between academic performance and social competence. Previous research has demonstrated that such relationship exists. For instance, McClelland, Acock, and Morrison (2006) found that, students who had poor self-control at the end of kindergarten received lower scores in reading and math in $1^{\text {st }}$ and $2^{\text {nd }}$ grade. This study also showed that self-control was positively linked to academic performance. 


\section{CHAPTER IV: ANALYSIS}

\section{INTRODUCTION}

My research exploring the effectiveness of conventional and Montessori educational models with respect to student academic and social outcomes was guided by three questions. The first question concerned academic performance of students in public schools that implement a Montessori model compared to students who attend conventional public schools. The second question explored the outcomes regarding social competencies of students attending public schools that implement a Montessori model compared to students who attend conventional public school. Finally, the third question investigated the link between students' academic performance and their social competencies.

In order to answer these questions, I conducted descriptive and comparative analyses of data for the four public schools I selected for this study. No advanced statistical methods were used as the data available from the Illinois School Report Cards and the 5Essentials Surveys were aggregated and expressed in percentages.

Aggregate data are composed of data about individual cases presented at a group level (Vogt 2005). As pointed out in the literature, aggregate data are often used in social science research instead of individual data (Borgatti 2002; Jacob 2016; Jacob 2014). Using aggregate data not only reduce the cost associated with securing individual data but in some instances becomes the only data type available to conduct a study as obtaining individual-level data is difficult and puts burden on institutions releasing them. While working with aggregate data presents studies with a number of limitations (ex. ecological fallacies), some researchers argue that in case that obtaining individual-level data is difficult, we should use aggregate data if such exist. They argue that "aggregate data will yield exactly the same results as individual-level data 
when two conditions hold" (Jacob 2016:2). The first condition requires that data are balanced. This implies "the same number of individuals in each group by which the data are being aggregated" such as the same number of students per school (Jacob 2016:2). The second condition assumes that there are no covariates involved in estimating the relationships. I believe that data selected for my study meets these two criteria.

Furthermore, statistical analysis that involves procedures such as correlation coefficients or significance tests is usually used when we engage in inferential statistics. The inferential statistics is "concerned with generalizing or inferring characteristics of the population from a subset of elements (sample) selected from that larger entity" (Leonard 1995:394). Therefore, we engage in inferential statistics when we rely on a sample drawn from a larger population to predict the numerical characteristics of the population (Leonard 1995). In the case of my study, I relied on data for a whole population in those four schools and already had access to the characteristics of the whole population. Therefore, I was unable to engage in statistical procedures such as correlation coefficients or significance tests. I, however, conducted descriptive and comparative analyses involving cross tabulations. These analyses are organized in three sections: school demographics, academic performance, and social competence. Figure 1 provides details.

Figure 1

Sections of Analysis

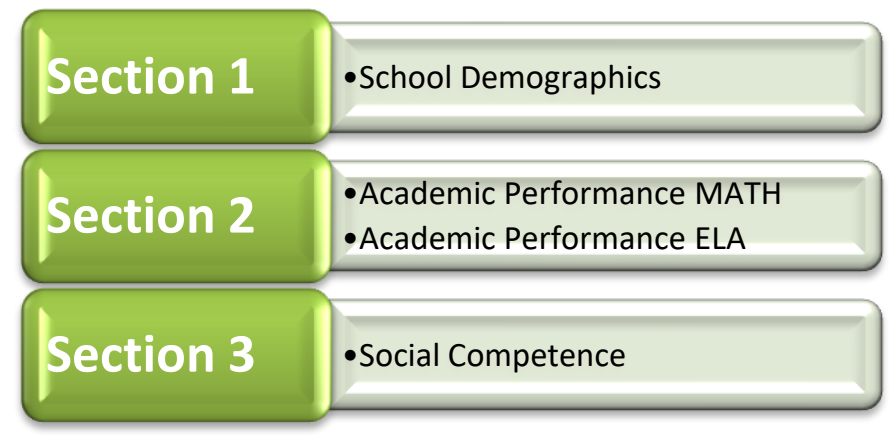




\section{Descriptive Analysis}

The first section presents a descriptive analysis of a demographic composition of individual schools (MLI, MHI, CLI, and CHI). In the second section, I analyzed each schools' academic performance in Math and ELA. To do so, I averaged the percentages of students in all four grades who performed at Level 1 (by adding up the percentages of students in each grade who performed at Level 1 and dividing this sum by four since I used data from $3^{\text {rd }}, 4^{\text {th }}, 5^{\text {th }}$, and $6^{\text {th }}$ grades). This approach allowed me to capture the overall percentage of students in each school who did not meet performance expectations in Math and ELA. I also averaged the percentages of students in all four grades who performed at Level 4 and Level 5 to capture the overall percentage of students who met or exceeded performance expectations. See Figure 2 for levels of performance considered in the analysis.

Figure 2

Analytical Levels of Performance

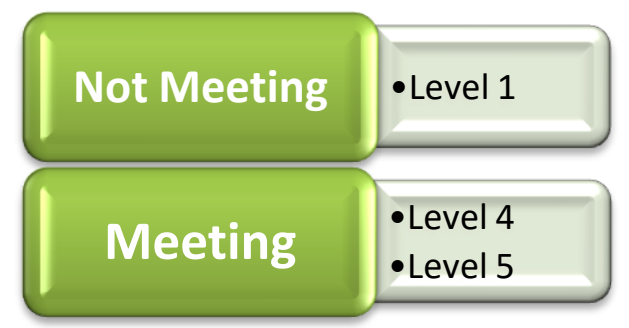

Finally, I conducted an analysis of each school's data on social skills (cooperation, responsibility, and self-control). Data on cooperation derived from teachers' assessments of their students in respect to four statements provided in the survey. I attained data on responsibility from teachers' assessments of their students in respect to three statements provided in the survey. Similarly, data on self-control came from teachers' assessments of their students in respect to three statements provided in the survey. Data on each skill was an average calculated by 
combining the data on individual statements and dividing them by the number of statements in each category. See Figure 3.

Figure 3

Social Skills

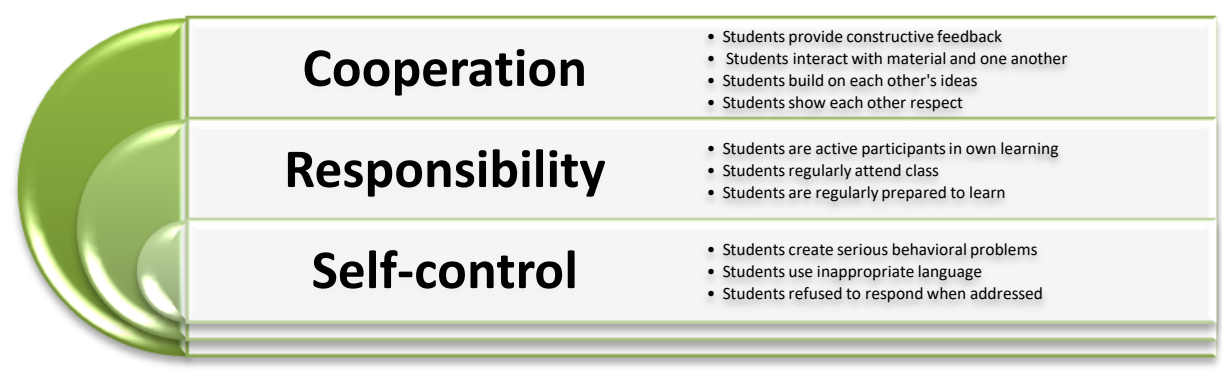

\section{Comparative Analysis}

In order to address my research questions, I also engaged in a comparative analysis that similarly to descriptive analysis was organized in three sections: demographics, school performance (ELA and Math) as well as social competence of students in schools selected for the study. The comparative analysis was conducted at two levels of data: grouped and individual schools. In order to create grouped data level, I combined data on low income and high income Montessori schools to capture the average demographics, academic performance and social competence of students attending both Montessori schools (MS). A similar procedure was employed to capture the average demographics, academic performance and social competence of students attending both conventional schools (CS). On the other hand, individual school data were used to compare schools with similar demographics (ML-CL; MH-CH) and different demographics (ML-CH; MH - CL). Figure 4 displays these comparisons. 
Figure 4

Comparisons
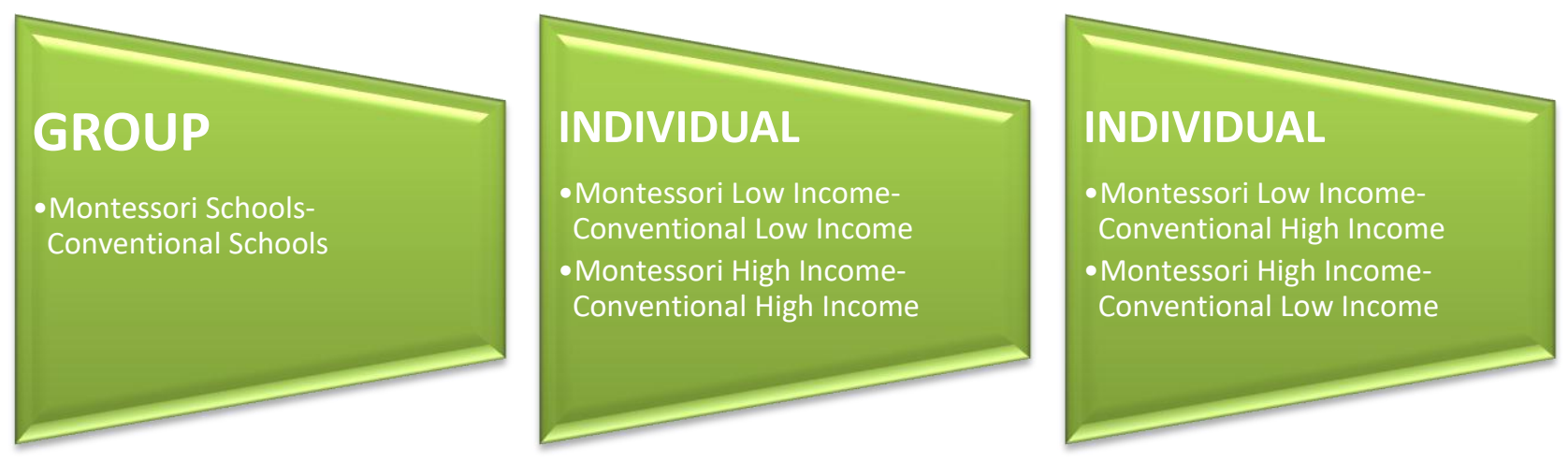

At the grouped data (MS-CS), academic performance was examined at two levels (L1"not meeting expectations", and L4-5 - "meeting expectations") with each level representing an average percent of students in both schools (MLI and MHI or CLI and CHI) who performed at a respectful level. To examine group (MS and CS) social competence, I averaged data on individual skills in each school to capture overall percentage of students attending both Montessori schools who exhibited cooperation, displayed responsibility, and engaged in selfcontrol. The same procedure was used to capture the level of social competence among students who attended conventional schools. At the second level of data (ML-CL, MH-CH and ML-CH, MH-CL), academic performance and social competence were analyzed in a similar manner to descriptive analysis.

\section{DESCRIPTIVE ANALYSIS}

\section{School Characteristics}

Demographic data derived from 2016-2017 Illinois Report Cards for each school selected for this study. Data were aggregated and expressed in percentages. See Table 4 for details. 
Table 4

Characteristics of School Population in Percentages by School

\begin{tabular}{lccccccc}
\hline & Size & $\begin{array}{c}\text { Lunch } \\
\text { Eligibility }\end{array}$ & & \multicolumn{3}{c}{ Race } \\
\hline School & & & White & $\begin{array}{c}\text { African } \\
\text { American }\end{array}$ & Hispanic & Asian & Other \\
& & & & & & & \\
\hline Montessori Low Income & 406 & 54.2 & 16.5 & 61.1 & 12.0 & 5.2 & 4.4 \\
Montessori High Income & 344 & 30.5 & 40.1 & 6.1 & 38.1 & 4.9 & 10.8 \\
Conventional Low Income & 701 & 58.3 & 16.1 & 63.1 & 8.4 & 6.1 & 6.2 \\
Conventional High Income & 409 & 20.0 & 59.2 & 1.5 & 30.6 & 5.1 & 3.6 \\
\hline
\end{tabular}

\section{Montessori low income school (MLI)}

During the 2016-2017, there were 406 students enrolled in MLI. About 54.2 percent of students attending this school were eligible for free or reduced price lunch. The ethnic and racial identifications of students attending this school were as follows: 16.5 percent identified as White; 61.1 percent as African American, 12 percent as Hispanic, 5.2 percent as Asian. Students who identified as Native Americans, Pacific Islanders or claimed two or more races were 4.2 percent of the school population. Characteristics of the MLI are displayed in Table 4.

\section{Montessori high income school (MHI)}

In MHI, there were 344 students enrolled during the 2016-2017. About 30.5 percent of students attending this school were eligible for free or reduced price lunch. In terms of the racial and ethnic composition of students, 40.1 percent identified as White, 6.1 percent as African American, 38.1 percent as Hispanic, and 4.9 percent as Asian. Students who identified as Native Americans, Pacific Islanders or claimed two or more races made up 4.9 percent of the school population. Characteristics of MHI are shown in Table 4.

\section{Conventional low income school (CLI)}

During the 2016-2017, there were 701 students enrolled in CLI. About 58.3 percent of students attending this school were eligible for free or reduced price lunch. The ethnic and racial identifications of students attending this school were as follows: 16.1 percent - White; 63.1 
percent - African American, 8.4 percent - Hispanic, 6.1 percent - Asian. Students who identified as Native Americans, Pacific Islanders or claimed two or more races made up 6.2 percent of the school population. Table 4 displays these characteristics.

\section{Conventional high income school (CHI)}

There were 409 students enrolled in CHI during 2016-2017 school year. About 20 percent of students attending this school were eligible for free or reduced price lunch. In terms of the racial and ethnic composition of students, 59.2 percent identified as White, 1.5 percent as African American, 30.6 percent as Hispanic, and 5.1 percent as Asian. Students who identified as Native Americans, Pacific Islanders or claimed two or more races made up 3.6 percent of the school population. See Table 4 for details.

\section{Academic Performance in Math and ELA}

To measure academic performance in Math and ELA, I relied on data from 2017 school report cards that derived from the 2016-2017 academic year of standardized Math and ELA tests scores for students from $3^{\text {rd }}$ through $6^{\text {th }}$ grade. As mentioned in the methodology section, the data on student academic performance have been measured with the help of PARCC standardized tests and reflect the percentage of students performing at specific levels. Data for each school was analyzed by subject (Math and ELA), individual grades $\left(3^{\text {rd }}-6^{\text {th }}\right)$ and two levels of performance ("Not Meeting" and "Meeting"). Individual Level Data for Math and ELA are provided in Appendix C.

\section{Montessori low income school (MLI)}

During 2016-2017, the greatest percentage of students who met or exceeded performance expectations in Math were $3^{\text {rd }}$ graders (35.7 percent). The greatest percentage of students who met or exceeded performance expectations in ELA were also $3^{\text {rd }}$ grade ( 42.9 percent). The 
smallest percentage of students who didn't meet the expectations in Math were also $3^{\text {rd }}$ graders (21.4 percent), followed by $5^{\text {th }}$ graders $(21.7$ percent). In regards to ELA performance, the smallest percentage of students who didn't meet the expectations were in $5^{\text {th }}$ grade (15 percent).

Details are provided in Table 5.

Table 5

MLI: Math-ELA Expectations

\begin{tabular}{ccccc}
\hline \multicolumn{5}{c}{ Expectations } \\
\hline Grades & 3 & 4 & 5 & 6 \\
\hline MATH & Meeting & & & \\
ELA & 35.7 & 5.0 & 21.7 & 16.7 \\
& 42.9 & 5.3 & 15.0 & \\
MATH & Not Meeting & & & 30.6 \\
ELA & 21.4 & 37.5 & 21.7 & 20.6 \\
\hline
\end{tabular}

Montessori high income school (MHI)

In 2016-2017 cohort of MHI school, the greatest percentage of students who met or exceeded performance expectations as measured by the standardized test in Math were $6^{\text {th }}$ graders (54.5 percent). The greatest percentage of students who met or exceeded performance expectations in ELA were in 4th grade (73.3 percent). The smallest percentage of students who didn't meet expectations in Math and ELA were 6th graders ( 0 percent). Table 6 shows the details. 
Table 6

MHI: Math-ELA Expectations

\begin{tabular}{ccccc}
\hline \multicolumn{5}{c}{ Expectations } \\
\hline Grades & 3 & 4 & 5 & 6 \\
MATH & Meeting & & & \\
ELA & 36.4 & 47.4 & N/A & 54.5 \\
& 54.2 & 73.3 & N/A & 54.5 \\
MATH & Not Meeting & & & \\
ELA & 9.1 & 10.5 & N/A & 0.0 \\
& 4.2 & 13.3 & N/A & 0.0 \\
\hline
\end{tabular}

Conventional low income school (CLI)

During 2016-2017, the greatest percentage of students who met or exceeded performance expectations in Math and ELA were $3^{\text {rd }}$ graders (53.5 percent and 51.7 percent). The smallest percentage of students who didn't meet the expectations in Math were $5^{\text {th }}$ graders $(3.2$ percent $)$ and in ELA were students in 4th grade (3.2 percent). See Table 7 for details.

Table 7

CLI: Math-ELA Expectations

\begin{tabular}{ccccc}
\hline \multicolumn{5}{c}{ Expectations } \\
\hline Grades & 3 & 4 & 5 & 6 \\
\hline MATH & Meeting & & & \\
ELA & 53.5 & 46.8 & 32.8 & 34.0 \\
& 51.7 & 50.8 & & \\
MATH & Not Meeting & & 3.2 & 11.4 \\
ELA & 8.6 & 6.5 & 10.3 & 14.0 \\
\hline
\end{tabular}

\section{Conventional high income school (CHI)}

In 2016-2017 school year, the greatest percentage of students who met or exceeded expectations in Math and in ELA performance in CHI were $3^{\text {rd }}$ graders $(80.4$ percent and 87.5 percent). The smallest percentage of students who didn't meet expectations in Math and ELA were in $4^{\text {th }}$ grade ( 2 percent and 2 percent). Refer to Table 8 for details. 
Table 8

CHI: Math-ELA Expectations

\begin{tabular}{ccccc}
\hline \multicolumn{5}{c}{ Expectations } \\
\hline Grades & 3 & 4 & 5 & 6 \\
\hline MATH & Meeting & 70.0 & 65.5 & 52.0 \\
ELA & 80.4 & 68.0 & 63.4 & 40.0 \\
& 87.5 & & & \\
MATH & Not Meeting & & 6.9 & 8.0 \\
ELA & 3.6 & 2.0 & 3.3 & 12.0 \\
\hline
\end{tabular}

Overall, across these four schools the greatest percentages of students who met or exceeded the expectations in Math for their grade levels were in $3^{\text {rd }}$ grade with an exception of the $6^{\text {th }}$ grade students in MHI school. Similarly to Math performance, schools with the greatest percentages of students who met or exceeded the expectations in ELA for their grade levels were in 3rd grade with an exception of the 4th grade students in MHI school. Furthermore, the smallest percentage of students not meeting the expectations in Math and ELA in high income schools was in 6th grade $(\mathrm{MHI})$ and 4 th grade $(\mathrm{CHI})$.

\section{Social Competence}

To measure student level of social competence, I used data from teacher assessments compiled in the 5Essetnials Survey Reports for 2016-2017 academic year. Social Competence of each school was analyzed separately by relying on data on cooperation, responsibility, and selfcontrol. Individual Skill Data are provided in Appendix D.

\section{Montessori low income school (MLI)}

According to teacher assessments, a greater percentage of students attending the MLI school in 2016-2017 exhibited responsibility (46.7 percent), followed by cooperation (45 percent) and self-control (44.7 percent). Table 9 displays data. 
Table 9

Social Competence in Percentages by School

\begin{tabular}{ccccc}
\hline Skills & $\begin{array}{c}\text { Montessori } \\
\text { Low Income }\end{array}$ & $\begin{array}{c}\text { Montessori } \\
\text { High Income }\end{array}$ & $\begin{array}{c}\text { Conventional } \\
\text { Low Income }\end{array}$ & $\begin{array}{c}\text { Conventional } \\
\text { High Income }\end{array}$ \\
\hline Cooperation & 45.0 & 51.5 & 48.0 & 47.5 \\
Responsibility & 46.7 & 49.0 & 58.0 & 77.0 \\
Self-Control & 44.7 & 51.0 & 64.7 & 91.0 \\
\hline
\end{tabular}

Montessori high income school (MHI)

A greater percentage of students who attended MHI in 2016 were noted to engage in cooperation (51.5 percent), self-control (51 percent) and responsibility (49 percent). See Table 9 for details.

Conventional low income school (CLI)

In CLI, a greater percentage of students in 2016 exhibited self-control (64.7 percent), responsibility (58 percent) and cooperation (48 percent). Table 9 presents details.

Conventional high income school (CHI)

In 2015, a greater percentage of students attending CHI displayed self-control (91 percent), responsibility (77 percent) and cooperation (47.5 percent). See Table 9.

\section{COMPARATIVE ANALYSIS}

To answer my research questions, this analysis will be presented in three sections:

Section One: compares the average demographics, academic performance and social competence of students attending both Montessori schools (MS) and both conventional schools (CS).

Section Two: compares separately the demographics, academic performance and social competence of students attending low income schools (ML-CL), high income schools (MH-CH), and schools with different demographics (ML-CH, MH-CL).

Section Three: analyzes data on academic performance and individual social skills of students attending both Montessori schools (MS) and both conventional schools (CS), low income 
schools (ML-CL), high income schools (MH-CH), and schools with different demographics (ML-CH, MH-CL).

For the purpose of this comparative analysis, school demographic data also derived from 2016-2017 Illinois Report Card for each school selected for this study and were already introduced in the descriptive analysis.

In terms of academic performance in Math and ELA, the school that had a smaller percentages of students who perform at Level 1 ("Not Meeting" standards) and a higher percentage of students who performed at Level 4 and 5 ("Meeting-Exceeding" the expectations) was considered a higher performing school. Academic performance of each group was analyzed by comparing the overall percentage of students in all grades who performed at levels 1 and level 4-5 on Math and ELA standardized tests. Complete data are provided in Appendix E.

Finally, a school that had a greater percentage of students who displayed cooperation, responsibility, and self-control was considered a school with students who exhibited a higher level of social competencies when compared to other school(s) in the study. Individual Skill Level Data for each school are provided in Appendix D.

\section{Comparison of Montessori and Conventional Schools}

\section{School characteristics}

One of the premises of this research design was to identify schools that have similar characteristics. Table 10 shows averaged data on school composition of students attending two Montessori (MLI, MHI) and two conventional schools (CLI, CHI). 
Table 10

Characteristics of the Montessori and Conventional School Groups in Percentages

\begin{tabular}{ccc}
\hline Characteristics & Montessori Schools & Conventional Schools \\
\hline Size (actual) & 374 & 552 \\
Eligibility for Lunch & 45.4 & 38.3 \\
Race/Ethnicity & & \\
White & 27.4 & 38.6 \\
African American & 34.1 & 31.7 \\
Hispanic & 30.7 & 19.3 \\
Asian & 5.3 & 5.6 \\
Other & 7.6 & 5.0 \\
\hline
\end{tabular}

Data show that a greater number of students attended conventional schools when compared to a combined count of students attending both Montessori schools. In terms of race and ethnicity, overall, a greater percentage of White students and Asian students attended conventional schools. In contrast, a greater percentage of African American students, Hispanic students, as well as Native American, Pacific Islander or those who claim two or more races attended Montessori schools. In addition, a greater percentage of students attending Montessori schools was eligible for a free or reduced price lunch compared to percentage of students eligible for free/reduced price lunch who attended conventional schools.

\section{Academic performance}

In terms of academic performance when considering data on Montessori and conventional schools, overall, a greater percentage of students attending Montessori schools didn't meet Math and ELA performance expectations when compared to students attending conventional schools. On the other hand, a greater percentage of students attending conventional schools met and/or exceeded Math and ELA performance expectations. See Table 11 for details. 
Table 11

Montessori Schools-Conventional Schools: Academic Performance

\begin{tabular}{cccc}
\hline Subject & Montessori & Conventional \\
\hline & \multicolumn{3}{c}{ Meeting Expectations } \\
MATH & 32.9 & 55.6 \\
ELA & 40.4 & 53.0 \\
& & Not Meeting Expectations & 6.3 \\
MATH & 17.2 & & 8.0 \\
ELA & 11.6 & \\
\hline
\end{tabular}

\section{Social competence}

According to teachers' assessments, a greater percentage of students attending

Montessori schools were noted to exhibit cooperation when compared to the percentage to students attending conventional schools. However, the difference between students attending both Montessori and both conventional schools was small. In contrast to a percentage of students who attended Montessori schools, a greater percentage of students attending conventional schools were noted to engage in self-control. Overall, when the percentages of students who exhibited cooperation, responsibility, and self-control were averaged, students who attended conventional schools displayed greater overall social competence. Table 12 provides details.

Table 12

Social Competence: $M S$-CS

\begin{tabular}{ccc}
\hline Skill & Montessori & Conventional \\
\hline Cooperation & 48.3 & 47.8 \\
Responsibility & 47.8 & 67.5 \\
Self-Control & 47.8 & 77.8 \\
\hline
\end{tabular}

Comparison of Low Income Schools: MLI-CLI

\section{School characteristics}

When comparing demographic data of students attending Montessori low income school to students in conventional low income, a greater number of students attended conventional low income school when compared to Montessori low income schools. In terms of race and ethnicity, 
overall, these schools were attended by a greater percentage of African American students and a smaller percentage of White students. Montessori low income school was attended by a greater percentage of Hispanic students compared to conventional low income school. Students who identified as Asian and Other constituted a small and a similar percentage of students in both low income schools. Finally, a similar percentage of students in both schools was eligible for a free or reduced price lunch. Table 13 displays school characteristics.

Table 13

Characteristics of Low Income Montessori and Conventional School Groups in Percentages

\begin{tabular}{ccc}
\hline Characteristics & Montessori Low Income & Conventional Low Income \\
\hline Size (actual) & 408 & 702 \\
Eligibility for Lunch & 59.1 & 57.7 \\
Race/Ethnicity & & \\
White & 15.8 & 17.6 \\
African American & 61.6 & 62.1 \\
Hispanic & 12.5 & 7.7 \\
Asian & 5.6 & 6.6 \\
Other & 4.2 & 5.6 \\
\hline
\end{tabular}

Academic performance

When considering data on Montessori low income and conventional low income schools, overall, a greater percentage of students attending Montessori schools didn't meet Math and ELA performance expectations when compared to students attending conventional schools. On the other hand, a greater percentage of students attending conventional schools met and/or exceeded Math and ELA performance expectations. See Table 14.

Table 14

MLI-CLI: Academic Performance

\begin{tabular}{ccc}
\hline Subject & Montessori Low Income & Conventional Low Income \\
\hline & \multicolumn{3}{c}{ Meeting Expectations } \\
MATH & 19.8 & 44.3 \\
ELA & 20.2 & 41.2 \\
& & Not Meeting Expectations \\
MATH & 27.8 & 7.4 \\
ELA & 17.3 & 10.2 \\
\hline
\end{tabular}




\section{Social competence}

As assessed by teachers in these two schools, a greater percentage of students attending conventional low income school were noted to exhibit self-control when compared to the percentage to students attending Montessori low income school. While a greater percentage of students attending conventional low income school displayed cooperation, the difference between students attending both schools who exhibited this skill was small. Also, the smallest percentage of students who exhibited self-control attended Montessori low income school. Overall, students who attended conventional schools displayed greater social competence. Data are displayed in Table 15.

Table 15 Social Competence: $M L I-C L I$

\begin{tabular}{ccc}
\hline Skill & Montessori Low Income & Conventional Low Income \\
\hline Cooperation & 45.0 & 48.0 \\
Responsibility & 46.7 & 58.0 \\
Self-Control & 44.7 & 64.7 \\
\hline
\end{tabular}

Comparison of High Income Schools: $\mathrm{MHI}-\mathrm{CHI}$

\section{School characteristics}

Demographic data on students attending Montessori high income and conventional high income schools showed that a greater number of students attended conventional high income school when compared to Montessori high income schools. Refer to Table 16. 
Table 16

Characteristics of High Income Montessori and Conventional School Groups in Percentages

\begin{tabular}{ccc}
\hline Characteristics & Montessori High Income & Conventional High Income \\
\hline Size (actual) & 344 & 409 \\
Eligibility for Lunch & 30.5 & 20.00 \\
Race/Ethnicity & & \\
White & 40.1 & 59.2 \\
African American & 6.1 & 1.5 \\
Hispanic & 38.1 & 30.6 \\
Asian & 4.9 & 5.1 \\
Other & 10.8 & 3.6 \\
\hline
\end{tabular}

Furthermore, in terms of race and ethnicity, overall, these schools were attended by a greater percentage of White students and a smaller percentage of African American students. The percentages of students who identified as Hispanic and Asian were similar in both schools. On the other hand, Montessori high income school was attended by a greater percentage of students who identified as other compared to conventional high income school. In addition, a greater percentage of students attending Montessori high income school was eligible for a free or reduced price lunch compared to percentage of students eligible for free/reduced price lunch who attended conventional low school.

\section{Academic performance}

While a similar percentage of students in MHI and CHI performed at Level 1;

respectively 6.6 percent and 5.1 percent, a greater percentage of students attending MHI school didn't meet Math and ELA performance expectations when compared to students attending CHI school. On the other hand, a greater percentage of students attending CHI school met and/or exceeded Math performance expectations. In regards to ELA performance, while the percentages of students in MHI and CHI who performed at Level 1 and Level 4-5 were very similar; respectively for Level 1: 5.8 percent and 5.7 percent, and for Level 4 -5: 60.7 percent and 64.7 percent, overall CHI had a smaller percentage of students who didn't meet ELA performance 
expectations and a greater percentage of students who met ELA performance expectations.

Details are provided in Table 17.

Table 17

MHI-CHI Academic Performance

\begin{tabular}{|c|c|c|}
\hline Subject & Montessori High Income & Conventional High Income \\
\hline & \multicolumn{2}{|c|}{ Meeting Expectations } \\
\hline MATH & 46.1 & 67.0 \\
\hline ELA & 60.7 & 64.7 \\
\hline & \multicolumn{2}{|c|}{ Not Meeting Expectations } \\
\hline MATH & 6.5 & 5.1 \\
\hline ELA & 5.8 & 5.7 \\
\hline
\end{tabular}

\section{Social competence}

According to teachers in these two schools, a greater percentage of students attending CHI were noted to exhibit self-control when compared to the percentage to students attending MHI. On the other hand, a greater percentage of students attending MHI exhibited cooperation when compared to the percentages of students in CHI. Overall, students who attended conventional schools displayed greater social competence. See Table 18 for more information.

Table 18 Social Competence: $\mathrm{MHI}-\mathrm{CHI}$

\begin{tabular}{ccc}
\hline Skill & Montessori High Income & Conventional High Income \\
\hline Cooperation & 51.5 & 47.5 \\
Responsibility & 49.0 & 77.0 \\
Self-Control & 51.0 & 91.0 \\
\hline
\end{tabular}

Comparison of Schools with Different Demographics: MLI-CHI

\section{School characteristics}

According to demographic data on students attending MLI school and CHI school, about the same number of students attended these two schools. See Table 19. 
Table 19

Characteristics of High Income Montessori and Conventional School Groups in Percentages

\begin{tabular}{ccc}
\hline Characteristics & Montessori Low Income & Conventional High Income \\
\hline Size (actual) & 408 & 409 \\
Eligibility for Lunch & 59.1 & 20.0 \\
Race/Ethnicity & & \\
White & 15.8 & 59.2 \\
African American & 61.6 & 1.5 \\
Hispanic & 12.5 & 30.6 \\
Asian & 5.6 & 5.1 \\
Other & 4.2 & 3.6 \\
\hline
\end{tabular}

Moreover, MLI was attended by a smaller percentage of White students and a smaller percentage of Hispanic students. In contrast, a greater percentage of African American students attended MLI compared to CHI school. The percentages of students who identified as Asian or other were similar in both schools. In terms of eligibility for a free or reduced price lunch, a greater percentage of students attending MLI when compared to percentage of students in CHI qualified.

\section{Academic performance}

A greater percentage of students attending MLI when compared to the percentage of students in CHI didn't meet Math and ELA expectations. On the other hand, a greater percentage of students attending CHI when compared to MLI met performance expectations in Math and ELA. Table 20 shows details.

Table 20

MLI-CHI Academic Performance

\begin{tabular}{ccc}
\hline Subject & Montessori Low Income & Conventional High Income \\
\hline & \multicolumn{3}{c}{ Meeting Expectations } \\
MATH & 19.8 & \\
ELA & 20.2 & 67.0 \\
& & Not Meeting Expectations \\
MATH & 27.8 & 5.1 \\
ELA & 17.3 & 5.7 \\
\hline
\end{tabular}




\section{Social competence}

As assessed by teachers, a greater percentage of CHI students were noted to exhibit cooperation, responsibility, and self-control when compared to students in MLI. See Table 21.

Table 21

Social Competence: $M L I-C H I$

\begin{tabular}{ccc}
\hline Skill & Montessori Low Income & Conventional High Income \\
\hline Cooperation & 45.0 & 47.5 \\
Responsibility & 46.7 & 77.0 \\
Self-Control & 44.7 & 91.0 \\
\hline
\end{tabular}

Comparison of Schools with Different Demographics: MHI-CLI

\section{School characteristics}

When comparing demographic data on students attending MHI school and CLI school, a greater number of students attended CLI. In terms of race and ethnicity, overall, a greater percentage of White students, Hispanic students, and Other attended MHI. In contrast, a greater percentage of African American students attended CLI. In addition, a greater percentage of students attending CLI was eligible for a free or reduced price lunch compared to percentage of students eligible for free/reduced price lunch who attended MHI. Table 22 provides details.

Table 22

Characteristics of High Income Montessori and Low Income Conventional School in Percentages

\begin{tabular}{ccc}
\hline Characteristics & Montessori High Income & Conventional Low Income \\
\hline Size (actual) & 344 & 702 \\
Eligibility for Lunch & 30.5 & 57.7 \\
Race/Ethnicity & & \\
White & 40.1 & 17.6 \\
African American & 6.1 & 62.5 \\
Hispanic & 38.1 & 7.7 \\
Asian & 4.9 & 6.6 \\
Other & 10.8 & 5.6 \\
\hline
\end{tabular}




\section{Academic performance}

Data are provided in Appendix E. As shown in Table 23, a greater percentage of students attending CLI didn't meet expectations in Math and ELA performance when compared to a greater percentage of students in MHI.

Table 23

MHI-CLI Academic Performance

\begin{tabular}{|c|c|c|}
\hline Subject & Montessori High Income & Conventional Low Income \\
\hline & \multicolumn{2}{|c|}{ Meeting Expectations } \\
\hline MATH & 46.1 & 44.3 \\
\hline ELA & 60.7 & 41.2 \\
\hline & \multicolumn{2}{|c|}{ Not Meeting Expectations } \\
\hline MATH & 6.5 & 7.4 \\
\hline ELA & 5.8 & 10.2 \\
\hline
\end{tabular}

\section{Social competence}

According to teachers' assessments, a greater percentage of students attending MHI were noted to exhibit cooperation when compared to the percentage to students attending CLI. In contrast to a percentage of students who attended MHI, a greater percentage of students attending CLI were noted to engage in a self-control and exhibited responsibility. Table 24 displays data.

Table 24 Social Competence: $M H I-C L I$

\begin{tabular}{ccc}
\hline Skill & Montessori High Income & Conventional Low Income \\
\hline Cooperation & 51.5 & 48.0 \\
Responsibility & 49.0 & 58.0 \\
Self-Control & 51.0 & 64.7 \\
\hline
\end{tabular}

\section{Comparison of Academic Performance and Social Competence Combined}

In order to answer my third research questions, I analyzed data on academic performance and individual social skills. This part of the analysis will be presented in two parts: 
Part One: compares academic performance and social competence of students attending both Montessori schools (MS) and both conventional schools (CS).

Part Two: compares academic performance and social competence of students attending low income schools (ML-CL), high income schools (MH-CH), and schools with different demographics (ML-CH, MH-CL).

\section{Comparison of Montessori and conventional schools}

When comparing academic performance in Math, ELA, and social skills of students attending both types of schools, we found that that conventional schools not only had a smaller percentage who failed meeting Math performance expectations and a greater percentage of students who met expectations also were the schools in which a greater percentages of students were noted to display responsibility and self-control in contrast to Montessori schools. However, a greater percentage of students attending Montessori schools were noted to exhibit cooperation when comparing to the percentage of students in conventional schools. See Table 25 for details.

Table 25

Academic Performance and Social Skills: $M S-C S$

\begin{tabular}{ccc}
\hline Expectations/Skills & Montessori & Conventional \\
\hline & Math & Math \\
Meeting & 32.9 & 55.6 \\
Not Meeting & 17.2 & 6.3 \\
& & \\
Meeting & ELA & ELA \\
Not Meeting & 40.4 & 53.0 \\
& 11.6 & 7.9 \\
Cooperation & & \\
Responsibility & Skills & Skills \\
Self-control & 48.3 & 47.8 \\
& 47.8 & 67.5 \\
\hline
\end{tabular}




\section{Comparison of low income schools}

When comparing academic performance and social competence of students attending both low income schools, we found that a smaller percentage of students attending conventional school failed meeting Math and ELA performance expectations, a greater percentage of these students also met Math and ELA expectations, and had a greater percentage of students who displayed all three skills when compared to students who attended Montessori low income school. See Table 26.

Table 26

Academic Performance and Social Skills: $M L I-C L I$

\begin{tabular}{ccc}
\hline Expectations/Skills & Montessori Low Income & Conventional Low Income \\
\hline & Math & Math \\
Meeting & 19.8 & 44.3 \\
Not Meeting & 27.8 & 7.4 \\
& ELA & ELA \\
Meeting & 20.2 & 41.2 \\
Not Meeting & 17.3 & 10.2 \\
& & \\
Cooperation & Skills & Skills \\
Responsibility & 45.0 & 48.0 \\
Self-control & 46.7 & 58.0 \\
\hline
\end{tabular}

\section{Comparison of high income schools}

When comparing academic performance in Math and ELA as well as social skills of students attending high income schools, we found that that conventional schools had a smaller percentage of students who failed meeting Math and ELA performance expectations and a greater percentage of students who met expectations but also had a greater percentages of students who were noted to display responsibility and self-control in contrast to Montessori schools. However, a greater percentage of students attending Montessori schools were noted to exhibit cooperation when comparing to the percentage of students in conventional schools. In 
addition, the differences between the percentages of students in both schools who failed and met expectations were small. Specifically, the difference in percentages of students in MHI and CHI who didn't meet the expectations in Math was 1.4 percent, in ELA was 0.2 percent. Table 27 provides data.

Table 27

Academic Performance and Social Skills: $M H I-C H I$

\begin{tabular}{ccc}
\hline Expectations/Skills & Montessori High Income & Conventional High Income \\
\hline & Math & Math \\
Meeting & 46.1 & 67.0 \\
Not Meeting & 6.5 & 5.1 \\
& ELA & ELA \\
Meeting & 60.7 & 64.7 \\
Not Meeting & 5.8 & 5.7 \\
& Skills & Skills \\
Cooperation & 51.5 & 47.5 \\
Responsibility & 49.0 & 77.0 \\
Self-control & 51.0 & 91.0 \\
\hline
\end{tabular}

Comparison of schools with different demographics: MHI-CLI

When analyzing academic performance and social competence of MHI and CLI, we found that not only a smaller percentage of students who attended MHI failed performance expectations in Math and in ELA as well as a greater percentage of these students met expectations in Math and ELA but also a greater percentages of students who were noted to engaged in cooperation attended MHI. See Table 28. 
Table 28

Academic Performance and Social Skills: MHI-CLI

\begin{tabular}{ccc}
\hline Expectations/Skills & Montessori High Income & Conventional Low Income \\
\hline & Math & Math \\
Meeting & 46.1 & 44.3 \\
Not Meeting & 6.5 & 7.4 \\
& & \\
Meeting & ELA & ELA \\
Not Meeting & 60.7 & 41.2 \\
& 5.8 & 10.2 \\
Cooperation & & \\
Responsibility & Skills & Skills \\
Self-control & 51.5 & 48.0 \\
& 49.0 & 58.0 \\
\hline
\end{tabular}

Comparison of schools with different demographics: MLI-CHI

Finally, when comparing academic performance and social competence of MLI and CHI, we found that CHI had a smaller percentage of students who didn't meet Math and ELA expectations, a greater percentage of students who met Math and ELA expectations, and a greater percentage of these students were noted to engage in cooperation, display self-control and exhibit responsibility. Table 29 includes details.

Table 29

Academic Performance and Social Skills: MLI-CHI

\begin{tabular}{ccc}
\hline Expectations/Skills & Montessori Low Income & Conventional High Income \\
\hline & Math & Math \\
Meeting & 19.8 & 67.0 \\
Not Meeting & 27.8 & 5.1 \\
& & \\
Meeting & ELA & ELA \\
Not Meeting & 20.2 & 64.7 \\
& 17.3 & 5.7 \\
Cooperation & & \\
Responsibility & Skills & Skills \\
Self-control & 45.0 & 47.5 \\
& 46.7 & 77.0 \\
\hline
\end{tabular}




\section{CHAPTER V: DISCUSSION}

\section{INTRODUCTION}

Within the discipline of sociology, it has been well-established that the opportunities to succeed are greatly impacted by our ascribed and achieved characteristics. Since we cannot change the race, ethnicity, gender, or socioeconomic background we are born to, education becomes one of the most important social institutions that can improve our quality of life and ultimately increase our upward social mobility.

Studies continue to show that some students enter our public schools with poor reading and math skills and this skill gap is strongly correlated with student race and social class (Garcia and Weiss 2015; Putnam 2015). While the gap exist before students enter the school and school "plays only a minor role of alleviating or creating test score gaps" (Putnam 2015:162), the hope of the founding fathers of public education was to act "beyond all other devices of human origin, (as) a great equalizer of the condition of men" (Mann 1848). We know that those who struggle during the early years of their formal education are more likely to drop out of school, have fewer employment opportunities and are more likely to experience poverty, suffer bad health and engage in criminal activity (Fredricks et al. 2011). Therefore, improving the attainment rates among our most disadvantaged youth is a matter of national importance with significant implications for the students as well as our society.

Student performance is complex and an array of reasons can be used to explain school's inability to narrow the inequality gaps most research points to issues related to residential segregation and unequal school funding system. In attempts to improve the state of public schools in the USA, the federal government came up with initiatives such as "No Child Left Behind" or "Race to the Top". However, these initiatives created greater competition among 
schools for funds and ultimately have further reinforced disparities between schools. Other education organizations have been proposing a constructive approach to change in public education. This approach emphasizes a student-centered focus that recognizes student culture and past experiences. An example of such approach is Montessori educational model. Furthermore, studies examining students who were exposed or attended Montessori schools show positive academic and socio-behavioral outcomes.

The purpose of my study was to expand our understanding of academic performance and social competence of students attending conventional and Montessori schools with similar demographic characteristics. This study was guided by three research questions:

R1: How do students perform academically in public schools that implement a Montessori model compared to students who attend conventional public schools?

R2: What are the outcomes regarding social competencies of students who attend public schools that implement a Montessori model compared to students who attend conventional public school?

R3: What is the link between students' academic performance and their social competencies? Does it differ between students who attend schools that implement a Montessori model and conventional model?

In order to answer my research questions, I conducted descriptive and comparative analyses of data on academic performance in Math and ELA as reported in report card for schools 2016-2017 school year for each school considered in this study. In a similar manner but relying on data in the 5Essentials Survey Reports, I conducted descriptive and comparative analysis of student social skills (cooperation, responsibility, and self-control). I also engaged in descriptive and comparative analyses of school characteristics such as size, eligibility for a 
free/reduced lunch price, and racial composition of students attending these schools. This approach allowed me to examine levels of academic performance and social skills for students in each school involved in the study as well as the composition of individual schools.

\section{SUMMARY OF FINDINGS}

The results will be organized in four sections. The first section will report the overall results for schools characteristics. In the second section, I will provide the overall reports on academic performance. The third section will include results on social competencies. The last section will include the answers to my research questions.

\section{School Characteristics}

\section{Comparison of Montessori and conventional schools}

Based on data from 2016-2017 Illinois Report Cards for schools selected for this study, in contrast to Montessori schools, conventional schools were overall attended by a greater number of students, had a greater percentage of students who identified as White and Asian, and had a smaller percentage of students who were eligible for a free or reduced price lunch. In addition, Montessori schools, overall, had a greater percentage of students who identified as Native Americans, Pacific Islanders or claimed two or more races.

\section{Comparison of low income schools}

When comparing demographic data of students attending low income schools, a greater number of students attended conventional low income school while a greater percentage who attended Montessori low income school identified as Hispanic. In contrast to high income schools, both low income schools were attended by a greater percentage of African American students and a smaller percentage of White students. Furthermore, both low income schools had a greater percentage of students who were eligible for a free or reduced price lunch in 
comparison to high income schools. Students who identified as Asian and Other constituted a similar percentage of students in both low income schools.

\section{Comparison of high income schools}

Demographic data on students attending high income schools show that a greater number of students attended conventional high income school while a greater percentage of students who attended Montessori high income school identified as Hispanic. In comparison to low income schools, both high income schools were attended by a greater percentage of White students and a smaller percentage of African American students. Conventional high income school had a little bit greater percentage of students who identified as Asian while Montessori high income school had a greater percentage of students who identified as Native Americans, Pacific Islanders or claimed two or more races. In contrast to low income schools, both high income schools had a smaller percentage of students who were eligible for a free or reduced price lunch.

Overall, in comparison to Montessori high income school, the conventional high income school had a greater percentage of White students, a smaller percentage of African American students, and a smaller percentage of students who qualified for a free or reduced price lunch.

\section{Comparison of schools with different demographics}

When comparing demographic data on students attending Montessori low income school and conventional high income school, the same number of students attended these two schools. However, overall, the conventional high income school had a greater percentage of White students, a smaller percentage of African American students, and a smaller percentage of students who qualified for a free or reduced price lunch when compared to Montessori low income. 
Demographic data on students attending Montessori high income school and conventional low income school show that a greater number of students attended conventional low income. Overall, the Montessori high income school had a greater percentage of White students, a smaller percentage of African American students, and a smaller percentage of students who qualified for a free or reduced price lunch.

Overall, demographic data for 2016-2017 academic year reveal that a greater number of students attended conventional schools. A greater percentage of Hispanic students and students who identified as Native Americans, Pacific Islanders or claimed two or more races attended Montessori schools. Overall, a greater percentage of White students attended conventional students while Montessori schools were attended by a greater percentage of African American and students who were eligible for a free/reduced lunch price. When considering data on low income and high income schools, we find that low income schools are attended by a greater percentage of African American students and have a greater percentage of students eligible for a free/reduced lunch price when compared to high income schools.

\section{Academic Performance}

\section{Comparison of Montessori and conventional schools}

Relying on data on academic performance in Math and ELA as reported on 2016-2017 Illinois Report Cards for schools selected for this study, a smaller percentage of students who didn't meet Math and ELA expectations and a greater percentage of students who meet Math and ELA expectations attended conventional schools. There was a smaller overall difference in the percentages of students who fail and met performance expectations in ELA than it was in Math. 


\section{Comparison of low income schools}

When comparing data on academic performance of students attending both low income schools, we find that a smaller percentage of students who didn't meet Math and ELA expectations and a greater percentage of students who meet Math and ELA expectations attended CLI school.

\section{Comparison of high income schools}

Overall, data on academic performance of students attending both high income schools show that a smaller percentage of students who didn't meet Math and ELA expectations and a greater percentage of students who meet Math and ELA expectations attended conventional high income school. However, there was a small difference between the percentages of students in attending both schools in Math who performed at Level 1 and in ELA who performed at Level 1 or Level 4-5.

\section{Comparison of schools with different demographics}

In terms of academic performance of students who attended Montessori low income and conventional high income, data reveal that that a smaller percentage of students who didn't meet Math and ELA expectations and a greater percentage of students who meet Math and ELA expectations attended conventional high income school.

Data on academic performance in Math and ELA of students attending Montessori high income and conventional low income show that that a smaller percentage of students who didn't meet Math and ELA expectations and a greater percentage of students who meet Math and ELA expectations attended Montessori high income school.

These findings on academic performance suggest that overall a greater percentage of students attending conventional schools met performance expectations in Math and ELA as 
captured by standardized tests conducted in 2016-2017 academic school year with one exception. This one exception was noted when comparing data on academic performance of students attending Montessori high income and conventional low income. In this case, a greater percentage of students attending Montessori high income school met performance expectations in Math and ELA. Finally, overall the differences in the percentages of students who failed and met performance expectations in ELA were smaller and more similar between conventional and Montessori schools than they were in Math.

\section{Social Competence}

\section{Comparison of Montessori and conventional schools}

As assessed by teachers, a greater percentage of students attending Montessori schools were noted to exhibit cooperation while a greater percentage of students attending conventional schools displayed responsibility, and self-control. However, the difference in percentages of students who engaged in cooperation in both type of schools was small.

\section{Comparison of low income schools}

According to teachers, a greater percentage of students attending conventional low income exhibited cooperation, responsibility, and self-control. However, the difference in percentage of students who engaged in cooperation in both type of schools was small.

\section{Comparison of high income schools}

Data on social competence as reported by teacher reveal that, a greater percentage of students attending Montessori high income school were noted to engage in cooperation. In contrast, a greater percentage of students attending conventional high income were noted to displayed self-control and responsibility. 


\section{Comparison of schools with different demographics}

When comparing social competence of students attending Montessori low income and conventional high income schools, we find that a greater percentage of students in the conventional high income school was noted to exhibit cooperation, responsibility, and selfcontrol when compared to students in Montessori low income.

In terms of social competence, when considering data on Montessori high income and conventional low income schools, we find that a greater percentage of students attending Montessori high income school were noted to exhibit cooperation. In contrast, a greater percentage of students attending conventional low income school was noted to engage in a selfcontrol and exhibited responsibility. Table 30 shows details.

Table 30

Social Competence in Percentages by School

\begin{tabular}{lcccccc}
\hline \multicolumn{1}{c}{ Skills } & $\begin{array}{c}\text { Montessori } \\
\text { Schools }\end{array}$ & $\begin{array}{c}\text { Conventional } \\
\text { Schools }\end{array}$ & $\begin{array}{c}\text { Montessori } \\
\text { Low } \\
\text { Income }\end{array}$ & $\begin{array}{c}\text { Conventional } \\
\text { Low Income }\end{array}$ & $\begin{array}{c}\text { Montessori } \\
\text { High } \\
\text { Income }\end{array}$ & $\begin{array}{c}\text { Conventional } \\
\text { High Income }\end{array}$ \\
\hline Cooperation & 48.3 & 47.8 & 45.0 & 48.0 & 51.5 & 47.5 \\
Responsibility & 47.8 & 67.5 & 46.7 & 58.0 & 49.0 & 77.0 \\
Self-Control & 48.0 & 77.8 & 44.7 & 64.7 & 51.0 & 91.0 \\
\hline
\end{tabular}

Findings on social competence as reported by teachers on 5Essential Surveys suggest that overall a greater percentage of students attending conventional schools were noted to engage in cooperation, exhibit responsibility and display self-control with one exception. This exception was noted when considering data on cooperation. In the first case, when comparing Montessori schools data to conventional schools, we find that a greater percentage of students who attended Montessori schools were noted to display cooperation. In the second case, when comparing data on cooperation between Montessori high income and other schools, we also find that a greater percentage of students who attended Montessori high income school was noted to display cooperation. 


\section{Research Questions}

The analysis of the data regarding research questions was organized at two levels and therefore the answer to these questions will be presented in a similar manner. The first research question concerned student academic performance in public conventional schools and public schools that implement a Montessori model.

Specifically, data on both Montessori (MS) and conventional schools (CS) as well as low income schools (MLI, CLI), high income schools (MHI, CHI), and low income Montessori (MLI) and a high income conventional (CHI) reveal that overall students who attended conventional schools met and/or exceeded performance expectations in Math and ELA at a greater percentage when compared to students in Montessori schools. Therefore, this data suggest that students attending conventional schools in this sample performed academically better than students at Montessori schools did. When comparing data on academic performance of students attending MHI and CLI, data suggest that a greater percentage of students attending MHI met performance expectations in Math and ELA.

The second research question involved student level of social competence in public conventional schools and public schools that implement a Montessori model. The analysis of data on social skills such as cooperation, responsibility, and self-control suggest that overall students attending conventional schools exhibited a greater level of responsibility and selfcontrol when compared to Montessori schools. However, students attending Montessori schools and specifically MHI exhibited a greater level of cooperation.

To answer my third research questions concerning a link between academic performance and social competence, data show that overall schools that had a greater percentage of students who met/exceeded academic performance in Math and ELA also were noted at a greater 
percentage to exhibit cooperation, responsibility and self-control. In case of Montessori schools this was true in regards to academic performance especially in ELA and percentage of students exhibiting cooperation. These findings suggest that a link between academic performance and social competence might exist in schools selected for this study.

\section{DISCUSSION OF FINDINGS}

The primary purpose of this research was to explore the effectiveness of conventional and Montessori educational models with respect to student academic and social outcomes. Overall, several findings were consisted with prior research. This section will be organized in five sections: school characteristics, academic performance, social competence, a link between academic performance and social competence, and school funding. While none of the research questions specifically required an analysis of school demographics or comments regarding school funding, the composition of student body in each school was fundamental to my research design and school funding is an important factor of student success. Therefore, both require to be mentioned.

\section{Characteristics of Schools}

\section{Montessori schools group - conventional schools group}

This study showed that a greater percentage of students in this sample attended conventional schools. This might suggest that Montessori schools in urban areas are not as popular as conventional schools are and therefore conventional schools remain the dominant source of formal education in urban areas. This observation is also confirmed when considering schools in the CPS where over 400 elementary schools are public conventional (CPS 2018) and six are public Montessori (US Montessori Census 2017). In terms of race and ethnicity, it appears that Montessori group in this sample was more diverse and included a larger percent of 
minority students. This aligns with prior literature on goals of brining Montessori method to public schools in an attempt to create more diverse classrooms (Jacobson 2007). Finally, as explored in prior works, schools that are attended by a greater proportion of minority students tend to have a higher number of low income or economically disadvantaged students (Kozol 2005; Putnam 2015; Rooks 2015). In sync with these findings, the Montessori school sample in my study had a greater percentage of minority students and a greater percentage of students eligible for a free or reduced lunch.

Montessori low income school - conventional low income school

The analysis of low income schools characteristics suggests that low income schools are attended by a greater percentage of African American students and a greater percentage of students who are eligible for a free/reduced price lunch. These findings aligned with prior literature pointing out that minority groups have been historically at a disadvantaged (Kozol 2005; Putnam 2015).

\section{Montessori high income school - conventional high income school}

The analysis of the characteristics of both high income schools suggested that in contrast to low income schools, the high income schools are attended by a greater percentage of White students and very small percentage of African American students. In addition, the difference between the percentage of White and African American students in high income conventional school was much greater than it was in low income conventional school. In contrast, the difference between the percentage of White and African American students attending a high income Montessori school was much smaller than it was in a high income conventional schools. The difference between the percentage of White and African American students attending low income Montessori school was closer to the difference seen in low income conventional school. 
These findings might suggest that overall White students are more evenly distributed among conventional and Montessori low income schools while African American students are overrepresented in low income schools and underrepresented in high income schools. This distribution of students in high and low income schools reflects the distribution of income by race among American population (Pew Research Center 2016).

These data also confirm prior studies pointing out that minority groups have been historically in more disadvantageous positions and we continue to witness a class-based residential segregation that perpetuates de facto class-based school segregation by placing highincome and low-income students into separate schools (Kozol 2005; Putnam 2015; Rooks 2015).

\section{Academic Performance}

In terms of academic performance, when comparing data for conventional (CS) and Montessori schools (MS), high income schools (CH-MH), as well as low income schools (CLML), students attending conventional schools met performance expectations in Math and ELA at a greater percentage when compared to students attending Montessori schools. Overall, the differences in performances among schools were smaller in ELA then they were in Math. On the other hand, when comparing data on academic performance of students attending MHI and CLI, a greater percentage of students attending MHI met performance expectations in Math and ELA.

These findings, on one hand, appear contradictory to prior nine studies (Erwin et.al 2010; Karnes et al. 1983; Miller and Bizzell 1984; Moody and Riga 2011; Peng 2009) that showed Montessori students outperformed students attending conventional schools in Math and Reading but are consistent with other twelve studies (Brown 2016; Dohrmann et al. 2007; Fero 2007; Lillard and Este-Quest 2006; Mallet and Schroeder 2015) that found "mixed outcomes" with conventional schools students outperforming in some areas but not others. 
Furthermore, when considering academic performance of students attending low and high income schools regardless of the type of school (conventional or Montessori), these data showed that students attending high income schools outperformed students attending low income schools. These findings are consistent with prior research suggesting that there is an achievement gap between children from high- and low-income families (Putnam 2015). Some explained that "that gap corresponds (...) to the high-income kids getting several more years of schooling than their low-income counterparts" (Putnam 2015:161). Others contribute these disparities in achievement of low- and high-income students to segregated inner-city schools that place highincome and low-income students into separate schools that have very different access to resources (Bowles and Gintis 1976; Coleman 1966; Kozol 2005; Putnam 2015).

Due to a limited number of public Montessori schools located within the geographical parameters of the study, Montessori school with 30.5 percent of students eligible for a free or reduced price lunch was coded as a high income school. When considering student composition of Montessori high income school to student composition of conventional low income school, both school are more similar in the percentages of students eligible for free or reduced lunch than they are to the percentage of students eligible for free or reduced lunch at the conventional high income schools. When comparing performance in Math and ELA of students attending high income Montessori and low income conventional school, data suggested and confirmed prior studies (Kozol 2005; Putnam 2015; Rooks 2015) indicating that students who attended high income schools outperformed students attending other low-income schools. Findings revealing a higher performance of Montessori students in ELA when compared to students in conventional schools also align with prior research concluding that Montessori students showed greater gains on outcome measures of reading and vocabulary (Lillard 2012), wrote more sophisticated and 
creative stories (Lillard and Else-Quest 2006), and passed reading assessment at a greater percentage when compared to students in conventional schools (Mallett and Schroeder 2015; Moody and Riga 2011).

\section{Social Competence}

While academic performance can be a predictor of one's future success, I have argued that social competencies are necessary for healthy and positive navigation of social environments (Durlak et al. 2011), show positive outcomes on workplace readiness, work performance, and well-being (Children Trends; Durlak et al. 2011), and might be a main outcome of education (Frey and Bos 2012). For the purpose of my study, I borrowed the definition of social competencies from ChildrenTrends and operationalized it as a set of skills necessary to get along, act positively with a group while achieving goals. I specifically focused on three skills: cooperation, self-control, and responsibility.

Data findings on social competence as used in this study suggested that overall a greater percentage of students attending conventional schools were noted to exhibit responsibility and display self-control. Studies involving brain development and early childhood experiences reveal that self-control is one of the brain's main functions along with working memory and mental flexibility (Harvard University 2011). Children are not born with these functions but they have the greatest potential to develop them in their early stages of development. Research also points out that self-control, in addition to other social skills, is required for a daily life and professional success (Harvard University 2011; Ballantine and Hammock 2012). Therefore, data findings in this study suggest that a greater percentage of students who attended conventional schools possessed self-control necessary to navigate a daily life and achieve professional success as defined within current discourse. 
Since self-control is an important social skill, future research could examine it in the context of authority. Briefly, from the conflict theory within the sociological discipline, schools control people, reinforce status quo, and produce obedient adult workers. Therefore, the findings indicating that a greater percentage of students attending conventional schools displayed selfcontrol might suggest that teaching and learning self-control is an important part of the conventional schools hidden curriculum. In addition, since these data are based on teachers' assessments of their students and teachers are also trained to teach their students the values accepted by the mainstream discourse, these findings might suggest that teachers who completed these assessments were better prepared to assess student levels of self-control. Finally, it is possible that students in conventional schools were provided with more activities and opportunities that allowed for a greater display of their high levels of self-control.

On the other hand, a greater percentage of students who attended Montessori schools and specifically, the high income Montessori school, were noted to engage in cooperation. These findings align with literature on Montessori model indicating that this method promotes cooperation over competition and emphasizes community rather individual success (Lillard 2012). For instance, some explain that students at Montessori schools have access to limited sets of learning materials and this might signify the importance of sharing and cooperation with other students (Lillard 2012). While teachers in Montessori schools maintain their authority when overseeing student work without unnecessary interpretation and guiding the misbehaved students towards positive engagement, students regard their teachers as guides rather than representatives of authority (Tzuo 2007). It might be suggested that these arrangements might allow for more cooperative interactions between teachers and students. 
In addition, similarly to findings of a greater percentage of students exhibiting selfcontrol in conventional schools, in regards to a greater percentage of students displaying cooperation in Montessori schools and aligned with Montessori philosophy and training, these findings suggest that teachers in Montessori schools could be prepared better to assess student levels of cooperation. It might be also possible that students in Montessori schools were provided with more activities and opportunities that allowed them to display cooperation more frequently.

\section{Link Between Academic Performance and Social Competence}

Data findings indicating that overall schools that had a greater percentage of students who met/exceeded academic performance in Math and ELA also were noted at a greater percentage to exhibit cooperation, responsibility and self-control, align with prior studies (McClelland et al. 2006) revealing similar results. In as much as prior studies suggest that a link between academic performance and social competence exists, it is important to further investigate the interplay of these two concepts and the importance of fostering both.

\section{School Funding}

Literature (Kozol 2005; Putnam 2015; Rooks 2017) points out that school funding is one of the variables that impacts student academic performance and it is, undoubtedly, an important facet shaping student success. The relationship between student success and school funding was not a focus of this work and a different project might be better suited for elaborating on it, but this work requires, that at least at this point, I discuss it briefly.

As mentioned, public schools in the United States are funded by government. In addition, these funds derive from federal, state, and local sources. Under the federal rules, schools might qualify to receive funds to support low income students (Title I), English learners (Title III), students with disability (IDEA), neglected students (Title I (D)), or to improve Teachers Quality 
(Title II A) (NCES 2018). Specific formulas are used to determine the amounts of funds and some districts implement a School Based Budgeting model for distribution of those funds (CPS 2018).

Since public schools have been largely depended on local property, neighborhoods with higher property taxes provide greater funds to schools in their zones. Since students who attend schools in neighborhoods that provide fewer local funds cannot simply relocate or afford transportation to the schools in areas with higher property taxes, federal government could provide more substantial funds to students who have access to fewer resources. However, initiatives such as "No Child Left Behind" or "Race to the Top" made school funding depended on student performance on standardized tests or other scoring criteria and pushed students with a limited access to resources further behind students who attend schools with an access to greater resources (Celestin 2011).

When considering school funding, it is imperative that we do not assume that students in all schools start at the same level of capacities, have the same training and experiences in taking standardized tests or have access to the same non-school resources. These disparities in capacities, training/experiences, and non-school resources demand greater funds for schools with students who are limited in those dimensions. If we continue to rely on students' scores on standardized tests as an indicator of the effectiveness of the funds, we should assure that schools receive enough funds so all students can perform well on those tests.

\section{LIMITATIONS}

While this study expands on student academic performance and social competence in public conventional and public Montessori schools, it is limited by numerous factors. Specifically, when working with aggregated data, one has to be cautious not to engage in 
ecological or exception fallacies. Ecological fallacy refers to an interpretation of aggregated data and making conclusions about individuals. Exception fallacy involves making group conclusions based on exceptional cases.

Second, in the case of data driven from the surveys completed by teachers, it is possible that teachers' evaluations are biased. Teacher's assessments, to some degree, are shaped by their perceptions of students' race, ethnicity, gender, and family economic status. While large studies conducted on a national level confirm the consistency and validity of data collected by teacher's assessments (Children Trend 2014), teachers might be still prone to social desirability bias. Furthermore, it is very likely that the majority of the teachers who completed surveys were females and therefore there is a potential for gender bias in their assessments.

Third, since we don't ask students' parents to report their incomes, in order to secure data on school socioeconomic status, I relied on data on free or reduced price lunch eligibility. As literature reveals, socioeconomic status involves not only the economic status of the family but is also influenced by parents' education and occupation. Eligibility for free or reduced price lunch provides data on whether students are poor or not. But such is the nature of the scientific research. It cannot all be perfect.

Fourth, even though the study attempted to control for demographics of students attending these schools by purposely selecting two schools with more advantageous school demographics and two other schools with less advantageous school demographics, and were coded as "high income schools" and "low income schools", these pairs were not ideal. Since there is a limited number of public Montessori schools located within the geographical parameters of the study, a school with 30.5 percent and 20 percent of students eligible for free or reduced price lunch were coded as a high income school. 
Fifth, as indicated in prior studies involving Montessori schools, the issue of school fidelity to the principles of Montessori method is one of the most crucial matters. Due to limited time and financial resources, I relied on information available on schools' website to determine fidelity of these schools. While the public Montessori schools selected for this study offer mixed ages classrooms, use Montessori materials, and teachers are trained in Montessori method and certified by the AMS, they are also accountable for addressing the Common Core State Standards by having their students take standardized tests that ultimately reduces the implementation of the classic Montessori fidelity.

Sixth, since the study attempted to examine the effectiveness of conventional and Montessori methods in students academic performance and social competencies, it would be beneficial to know a little bit more about teachers' job experiences and their educational preferences.

Finally, studies show that students who were exposed to Montessori preschools experienced positive academic outcomes and in some cases these results were not seen until later grades. Unfortunately, I didn't have access to these data and therefore my findings remain limited.

\section{ETHICAL ISSUES}

When proceeding with secondary data, my study did not present any harm or risks to the research subjects since I was using public data that did not provide identifiable personal information of students or teachers.

\section{ANONYMITY AND CONFIDENTIALITY}

Student and teacher identities will never be disclosed because I never had access to them. During the process of the study data were stored securely at the Department of Sociology and 
Anthropology at Illinois State University. Data will be disseminated through publication and presentation in the form of aggregate results with no identifiers.

\section{IMPLICATIONS}

I believe that this study has several implications. For one, this study expands our understanding of the current state of academic performance and social competencies of students attending these four schools selected for the study. This, ultimately, provides for a discussion regarding student success.

Secondly, while schools can equip our students with knowledge and skills, for some (students historically at risk) otherwise unattainable, the effectiveness of those services as assessed by standardized tests and teachers' surveys by the schools selected for this study appears questionable. Since some funding and assessments of school performance is depended on student performance on standardized tests, we often hear that our public schools "teach to the test". It is also possible that the performance disparities between low income and high income schools are a product of conventional schools teaching to the test that requires using specific books that some students attending low income schools simply cannot afford. As a result, these standardized tests assess how well students can take a test rather than capture student level of knowledge and skills. Since the validity of these tests as an instrument measuring student performance has been questionable, this study adds to prior works that call policy makers, educational community organization, and conventional public school stakeholders to consider reevaluating current assessment instruments and developing evaluation tools that more adequately measure student progress.

Thirdly, while there is a vast number of studies exploring Montessori schools and some explore Montessori public elementary schools, my study not only emphasizes the importance of 
evaluating success of Montessori students within the context of their academic performance and social competencies in comparison to other conventional schools but suggests that there is a positive link between these two dimensions of student performance in both types of schools. These findings, therefore, support a further need to provide students in both types of schools with environments, activities, and resources that foster both positive academic performance and social skills.

Fourthly, my study adds to the prior body of research that found "mixed outcomes" with conventional students outperforming Montessori students in some areas but not others. This ultimately confirms and aligns with sociological theories on student performance that learning processes are complex and besides a pedagogical approach involve a number of variables that include but are not limited to resources, composition of students and staff, and teacher preferences.

Finally, this study clearly shows that some of our public schools remain separated and segregated despite changes in our legal system prohibiting discrimination against access to schools based on race, ethnicity or gender (Brown 1954), the Equal Educational Opportunity Act (1974), and policy programs such as Lyndon Johnson's “War on Poverty”. Most researchers believe the reasons behind our separated and segregated schools are residential segregation and unequal school funding system (Bowles and Gintis 1976; Kozol 2005; Putnam 2015). It was clear that low income schools in my study were attended by a greater percentage of students eligible for a free/reduced lunch and who were minorities. While I selected these four schools by employing a purposive sample, upon a closer review of public schools in the CPS, many schools in the southern part of this particular school district were closed and/or were attended by majority of Africa American students. Therefore, this study brings attention to larger structural 
and systematic problems and signals to politicians, researchers, and any other public school stakeholders to address residential segregation in attempts to provide all students with equal education.

\section{FUTURE RESEARCH}

For the purpose of my study, I relied on aggregate data and explained that these data are used in social science research for different reasons. While comparative studies that match demographics of individual students attending different schools are very helpful in understanding student performance, using aggregate data allows us to capture academic performance of schools rather than specific groups of students. Therefore, future research relying on aggregate data could expand on our understanding of the overall performance of our students attending different schools.

In light of my study, there is also a need for further research exploring assessment instruments we use to measure student performance. Future studies could focus on examining assessment tools such as standardized tests and the 5Essentials Surveys to determine their validity and potentially suggest improvements to assure they measure what they are intended to measure.

Within the context of research exploring student performance, we should not to forget about the importance of students and teachers' voices in capturing educational experiences. While there is a substantial body of research addressing the role of teachers in students' learning experiences, there is limited work on reflections describing students' experiences in public Montessori schools, and teachers' accounts that focus on helping students to develop social skills in public schools. Future studies, therefore, could examine accounts and reflections of students 
and teachers in both types of schools. Further works could also explore how teacher job experiences and their educational preferences impact student performance.

In addition, we need more research involving longitudinal studies. These longitudinal studies are better equipped to capture changes in student outcomes over time and therefore are better suited to measure the long term effects of learning methods. They also become helpful in identifying areas that need improvement and can be used to support educational policies that attempt to fulfill the promise of the founding fathers who proclaimed that "education, beyond all other devices of human origin, is a great equalizer of the conditions of men" (Mann 1848). 


\section{CHAPTER VI: CONCLUSION}

While the mainstream belief assumes that our success is a result of our talents, hard work, and commitments, studies continue to show that our ascribed characteristics such as our socioeconomic background as well as race and ethnicity not only greatly shape the quality of our life but are more advantageous for some than they are for other. Since we cannot change disadvantageous ascribed characteristics, education becomes one of the most important social institutions that can provide for our upper social mobility.

However, studies reveal that a substantial number of these students enter our public schools lacking skills in reading and math (Garcia and Weiss 2015). Furthermore, this skill gap is strongly correlated with student race and social class. While schools provide formal knowledge, they also provide opportunities for developing social competencies necessary for healthy and successful navigation of social environments (Durlak et. al 2011). Those who do well academically and socially are more likely to complete high school, have more opportunities for employment, engage in positive personal relationships and are less likely to experience poverty, bad health, or criminal activity (Durlak et al. 2011; Fredricks et al. 2011). Since school age children constitute a significant and growing part of the American population, improving student educational experiences not only impacts a large group of individuals but is a matter of national importance with significant implications for the students and society.

The purpose of this case study was to compare the state of academic performance and social competencies in two educational models employed in four public schools located in an urban area. The results of this study suggest that when relying on data from 2016-2017 Illinois Report Cards for each school selected for this study, overall students attending conventional schools performed academically better than students at Montessori schools did. In addition, when 
comparing data on academic performance of low income schools to high income schools used in this study, data show that students who attended high income schools outperformed students who attended low income schools.

In terms of social competencies, results were based on data provided in the 5Essentials Survey Reports and suggested that a greater percentage of students attending conventional school were noted to exhibit self-control and responsibility while a greater percentage of students attending Montessori schools was noted to engage in cooperation.

Finally, results also suggested that there could be a positive link between academic performance as well as self-control and responsibility among students who attended conventional schools in the sample. Also, results suggested that there could be a positive link between academic performance and cooperation among students who attended Montessori schools selected for this study.

Overall, since this study reinforces prior research concluding that socioeconomic background of students is a pivotal factor shaping their school success, future research could engage in studies expanding our understanding of a relationship between student socioeconomic status, parents' cultural capital, and school outcomes in different educational settings. In addition, further research could also investigate inequality of educational opportunities among public schools within a context of current push for school choice through charter schools and vouchers. 


\section{REFERENCES}

Adams, Pam. 2015. "PARCC test more complex, time-consuming than ISAT." JournalStar. Retrieved from http://www.pjstar.com/ article/20150225/ NEWS/150229487?start=3.

American American Humanist Association. 2018. Humanist Manifesto I. Retrieved from http://americanhumanist.org/Humanism/Humanist_Manifesto_I.

Apple, Michael W. 2003. The State and the Politics of Knowledge. New York, NY: RoutledgeFalmer.

Ballantine, Jeanne H. and Floyd M. Hammack. 2012. The Sociology of Education. A Systematic Analysis. Upper Saddle River NJ: Pearson Education, Inc.

Bennett deMarrais, Kathleen and Margaret D. LeCompte.1995. The way schools work: a sociological analysis of education. White Plains, NY: Longman.

Blau, Peter M. and Otis Dudley Duncan. 1967. The American Occupational Structure. New York: Wiley.

Borgatti, S. 2002. "A Statistical Method for Comparing Aggregate Data Across a Priori Groups."Field Methods 14(1): 88-107. Retrieved from https://pdfs.semanticscholar.org / 8aa1/ae13b88f4b7a0f88 aec022ed74c3a5500c44.pdf.

Bourdieu , Pierre. 1973. "Cultural Reproduction and Social Reproduction." in Knowledge, Education, and Cultural Change: Papers in the Sociology of Education, edited by R. K. Brown.

Bourdieu, Pierre and Jean Claude Passeron. 1977. "The Ideological Function of the Education System." Pp. 194-219 in Reproduction in Education, Society and Culture Beverly Hills: Sage Publications.

Bourdieu, Pierre. 1986. "The Forms of Capital." Pp. 241-258 in Handbook of Theory and Research for the Sociology of Education, edited by J. G. Richardson. New York: Greenwood.

Bowles, Samuel and Herbert Gintis. 1976. Schooling in capitalist America: educational reform and the contradictions of economic life. New York: Basic Books.

Brown, Katherine B. 2016. Evaluating the Effectiveness of Montessori Reading and Math Instruction for Third Grade African American Students in Urban Elementary Schools (Doctoral Disseratation). Retrieved from ProQuest Dissertations \& Theses Global. 
Celestin, John. 2011. "Public Education in America: How our Leaders Can Reinvigorate our Public School System.” Retrieved from http://www.eckerd.edu/ academics/ ford/files/11/John_Celestin.pdf.

Center on the Developing Child at Harvard University. 2011. Building the Brain's "Air Traffic Control" System: How Early Experiences Shape the Development of Executive Function: Working Paper No. 11. Retrieved from http://www.developingchild. harvard.edu.

Chauncey, Caroline and Nancy Wasler. 2009. Spotlight on student engagement, motivation, and achievement. Cambridge, Mass: Harvard Education Press.

Chicago Public Schools. 2017. CPS Stats and Facts. Retrieved from https://cps.edu/ About_CPS/At-a-glance/Pages/Stats_and_facts.aspx.

Chicago Public Schools. 2018. CPS Stats and Facts. Retrieved from https://cps.edu/ About_CPS/At-a-glance/Pages/Stats_and_facts.aspx.

Child Trends. 2014. Measuring Elementary School Students' Social and Emotional Skills: Providing Educators with Tools to Measure and Monitor Social and Emotional Skills that Lead to Academic Success. Child Trends Publication \#2014-37; Coleman, James S. 1966. Equality of Educational Opportunity. Washington U.S. Dept. of Health, Education, and Welfare, Office of Education.

Cisneros, M. M. 1994. Multiple measures of the effectiveness of public school Montessori education in the third grade (Doctoral dissertation). Retrieved from UMI (9424365).

Clifford, Alcillia J., and Carol Takacs. 1991. Marotta Montessori Schools of Cleveland follow-up study of urban center pupils. (Unpublished paper, Cleveland State University).

Coleman, James S. 1966. Equality of Educational Opportunity. Washington U.S. Dept. of Health, Education, and Welfare, Office of Education.

Chicago Public School. 2017. CPS Stats and Facts. Retrieved from https://cps.edu/ About_CPS/At-a-glance/Pages/Stats_and_facts.aspx.

Diekmann, Marius and Sabine Gruehn. 2013. Fostering Students' Social Competence - A Comparison of Montessori and Traditional Schools' Impact at the end of Secondary Level 1. Creativity and Innovation in Educational Research.

Dohrmann, Kathryn Rindskopf. 2003. Outcomes for students in a Montessori Program. A longitudinal Study of the Experience in the Milwaukee Public schools. AMI/USA.

Dohrmann, Kathryn Rindskopf, Tracy K. Nishida, Alan Gartner, Dorothy Kerzner Lipsky and Kevin J. Grimm. 2007. "High School Outcomes for Students in a Public Montessori Program." Journal of Research in Childhood Education 22(2): 205-17. 
Durlak, J. A., Weissberg, R. P., Dymnicki, A. B., Taylor, R. D. and Schellinger, K. B. 2011. "The Impact of Enhancing Students' Social and Emotional Learning: A Meta-Analysis of School-Based Universal Interventions." Child Development 82: 405-432.

Ervin, B., Wash, P. D., \& Mecca, M. E. 2010. “A 3-year study of self-regulation in Montessori and non-Montessori classrooms." Montessori Life 22(2): 22-31.

Fero, J. R. 1997. A comparison of academic achievement of students taught by the Montessori method and by traditional methods of instruction in the elementary grades (Doctoral dissertation). Retrieved from UMI (9729962).

Franczak, I. 2016. "Comparative Analysis of Behavioral Engagement and Transferable Skills in Conventional Public, Public Montessori, and Private Montessori Schools.” Proceedings of the NCUR 2016:811-820.

Fredricks, J., Wendy McColskey, Jane Meli, Joy Mordica, Bianca Montrosse, and Kathleen Mooney. 2011. "Measuring student engagement in upper elementary through high school: a description of 21 instruments. "(Issues \& Answers Report, REL 2011-No. 098). Washington, DC: U.S. Department of Education, Institute of Education Sciences, National Center for Education Evaluation and Regional Assistance, Regional Educational Laboratory Southeast. Retrieved from http://ies.ed.gov/ncee/edlabs.

Frey, K. A., and W. Bos. 2012. "A psychometric analysis of a large-scale social competence inventory for elementary school children." JERO 4(1): 20-46.

Furstenberg, Frank F., Jr., Thomas D. Cook, Jacquelynne S. Eccles, Glen H. Elder, Jr., and Arnold Sameroff. 1999. Managing to Make It: Urban Families and Adolescent Success. Chicago:University of Chicago Press.

Garcia, Emma and Elaine Weiss. 2015. Early Education Gaps by Social Class and Race Start U.S. Children Out on Unequal Footin. Economic Policy Institute. Retrieved from http://www .epi.org/publication/early-education-gaps-by-social-class -and-race-start-u-s -children-out-on-unequal-footing-a-summary-of-the-major-findings-in-inequalities-atthe-starting-gate/.

Gordon, Mordechai. 2009. "Toward a pragmatic discourse of constructivism: Reflections on lessons from practice." Educational Studies 45: 39-58.

Goslin, D. A. 2003. Engaging Minds. Motivation and Learning in America's School. Lanham MD: The Scarecrow Press, Inc.

Helfrich, M. Shannon. 2011. Montessori Learning in $21^{\text {st }}$ century. Troutdale, OR: NewSage Press. 
Herold, Benjamin. 2016. "PARCC Scores Lower for Students Who Took Exams on Computers." EducationWeek. Retrieved from https://www.edweek.org/ew/articles/2016/02/03/ parcc-scores- lower-on-computer.html.

Illinois Report Card. 2017. Retrieved from https://www.illinoisreportcard.com/.

Illinois State Board of Education. 2017. Retrieved from https://www.isbe.net/pages/socialemotional-learning-standards.aspx.

Illinois State Board of Education. 2017. Retrieved from https://www.isbe.net/Pages/PARCCPlace.aspx.

Illinois State Board of Education . 2018. Free and Reduced-Price Meal Eligibility Data. Retrieved from https://www.isbe.net/Pages/Seamless-Summer-Option-MealEligibility.aspx.

Jacob, R. 2014. "Assessing the Use of Aggregate Data in the Evaluation of School-Based Interventions: Implications for Evaluation. Research and State Policy Regarding Public Use Data. "Educational Evaluation and Policy Analysis 36(1): 44-66. Retrieved from http://journals.sagepub.com/doi/abs/10.3102/0162373713485814?journalCode=epa a.

Jacob, R. 2016. "Using Aggregate Administrative Data in Social Policy Research.” OPRE Report. Retrieved from https://www.acf.hhs.gov/sites/default/files/ opre/opre_brief_draft_dec2016_finaldraftjacob_clean_508.pdf.

Jacobson, L. 2007. “Taming Montessori.” Education Week 26(27), 30-32.

Jones, Bobbie and Louise B. Miller. 1979. Four Preschool Programs: Their Lasting Effects. [Washington, DC]: Distributed by ERIC Clearinghouse.

Karnes, M. B., Shwedel, A. M., and Williams, M. B. 1983. A comparison of five approaches for educating young children from low-income homes. In Consortium for Longitudinal Studies (Ed.), Pp. 133-171 in As the twig is bent: Lasting effects of preschool programs. Hillsdale, NJ: L. Erlbaum Associates.

Kayioi, Gokhan and Ozden Kuúcu. 2012.”Examination of Social Competence and School Adjustment of Primary School Children who had Pre-School Education with the Montessori Method." Journal of Teaching and Education 1(2): 399-405.

Kozol, Jonathan. 1992. Savage Inequalities: Children in America's Schools. New York: HarperPerennial.

Kozol, Jonathan. 2005. The Shame of the Nation: The Restoration of Apartheid Schooling in America. New York: Crown Publishers. 
Leonard, Wilbert M. 1995. Basic Social Statistics. Stipes Publishing Company.

Lillard, Angeline S. 2012. "Preschool children's development in classic Montessori, supplemented Montessori, and conventional programs." Journal of School Psychology 50: $379-401$.

Lillard, Angeline S. 2008. Montessori. The Science Behind the Genius. New York, NY: Oxford University Press Inc.

Lillard, Angeline and Nicole Else-Quest. 2006. "Evaluating Montessori Education.” Science 313 (5795): 1893-1894.

Mallett, Jan D. and Jennifer L. Schroeder. 2015. "Academic achievement outcomes: A comparison of Montessori and non-Montessori public elementary school students." Journal of Elementary Education 25(1): 39-53.

Mann, Horace. 1848. Twelfth Annual Report of Horace Mann as a Secretary of Massachusetts State Board of Education. Retrieved from https://genius.com/ Horace-mann-twelfthannual-report-to-the-secretary-of-the-massachusetts-state-board-of-education-1848annotated.

Martin, Robin A. 2004. "Philosophically Based Alternatives in Education." Education for Meaning and Social Justice 17 (1).

McClelland, M. M., Acock, A. C., \& Morrison, F. J. 2006. The impact of kindergarten learningrelated skills on academic trajectories at the end of elementary school. Early Childhood Research Quarterly, 21(4): 471-490.

McDurham, R. 2011. A Comparison of Academic Achievement for Seventh and Eighth Grade Students from Montessori and non-Montessori School Programs (Doctoral Dissertation) Retrieved from ProQuest Dissertations \& Theses Global.

Mickelson, Roslyn A. 1990. "The Attitude-Achievement Paradox among Black Adolescents." Sociology of Education 63: 44-61.

Miller, Louis B. and Rondeal P.Bizzell. 1983. "Long-Term Effects of Four Preschool Programs: Sixth, Seventh, and Eighth Grades." Child Development 54(3): 727-741.

Miller, Louis B., and Rondeal P. Bizzell. 1984." Long-term effects of four preschool programs: Ninth- and tenth-grade results." Child Development 55: 1570-1587.

Moody, M. J., \& Riga, G. 2011. Montessori: Education for life. In L. Howell, C. W. Lewis, \& N. Carter (Eds.), Pp. 127-143 in Yes we can!: Improving urban schools through innovative education reform. Charlotte, NC: Information Age Publishing. 
Mordechai, Gordon. 2009. "The misuses and effective uses of constructivist teaching." Teachers and Teaching 15(6).

National Charter School Resource Center. 2017. Retrieved from https://www.charter schoolcenter.org/.

National Center for Education Statistics. 2014. Retrieved from https://nces.ed.gov/.

National Center for Education Statistics. 2016. Retrieved from https://nces.ed.gov/.

National Center for Education Statistics. 2018. Retrieved from https://nces.ed.gov/.

North American Montessori Teachers' Association. 2018. Retrieved from http://www.montessori -namta.org.

Ochoa, Gilda L. 2013. Academic Profiling: Latinos, Asian Americans, and the Achievement Gap. Minneapolis, MN: University of Minnesota Press.

Ogbu, John U. and Herbert D. Simons. 1998. "Voluntary and Involuntary Minorities: A CulturalEcological Theory of School Performance with Some Implications for Education." Anthropology and Education Quarterly 29: 155-88.

Ogbu, John U. 2003. Black American Students in an Affluent Suburb: A Study of Academic Disengagement. Mahwah, NJ: Lawrence Erlbaum Associates, Inc.

PARCC. 2017. "2015-2016 Tables of Cross-State and State-Specific PARCC Results." Retrieved from https://www.politico.com/states/f/?id=00000158-73e6-dc8a-a15cfffe6d460000.

Peng, Hsin-Hui. 2009. A comparison of the achievement test performance of children who attended Montessori schools and those who attended non-Montessori schools in Taiwan. (Doctoral dissertation). Retrieved from ERIC (FirstSearch) (ED513608).

Pew Research Center. 2016. "On Views of Race and Inequality, Blacks and Whites are Worlds Apart.” Retrieved from http://www.pewsocialtrends.org/2016/06/27/1-demographictrends-and-economic-well-being/.

Putnam, Robert D. 2015. Our Kids: The American Dream in Crisis. New York, NY: Simon and Schuster.

Rooks, Noliwe. 2015. Cutting School: Privatization, Segregation, and the End of Public Education. New York, NY: The New Press.

Rose-Krasnor, Linda. 1997. "The Nature of Social Competence: A Theoretical Review.” Social Development 6: 111-135. 
Salazar, Minerva. 2014. The Impact of Montessori Teaching on Academic Achievement of Elementary School Students in a Central Texas School District: A Casual-Comparative Inquiry (Doctoral dissertation). Retrieved from Texas AM University.

Sciarra, Dorothy June, \& Anne Dorsey 1976. "Nine-year follow-up study of Montessori education." University of Cincinnati. Retrieved from ERIC: http://files.eric.ed.gov/ fulltext/ED121929.pdf.

Shankland, Rebecca, Christophe Genolini, Lionel R. Franca, Julien D. Guelfi, and Serban Ionescu. 2010. "Student adjustment to higher education: The role of alternative educational pathways in coping with the demands of student life." Higher Education 59(3): 353-366.

Stodolsky, S. S. 1970. "Ancona Montessori research project for culturally disadvantaged children: Final report.” Retrieved from ERIC: http://files.eric.ed.gov/ fulltext/ED133066.pdf.

Tzuo, Pei W. 2007. “The tension between Teacher Control and Children's Freedom in a childcentered Classroom: resolving the practical dilemma through a closer look at the related theories." Early Childhood Education Journal 35:1.

UChicago Consortium on School Research. 2017. Retrieved from https://consortium.uchicago.edu/ surveys.

US Department of Education. 2016. Fast Facts. Back to school statistics. Institute of Education Sciences. National Center for Education Statistics. Retrieved from http://nces.ed.gov/fastfacts/ display.asp?id=372.

US Montessori Census. 2017. Retrieved from http://www.montessoricensus.org/.

US Montessori Census. 2018. Retrieved from http://www.montessoricensus.org/.

Vogt, W. Paul. 2005. Dictionary of Statistics \& Methodology. A Nontechnical Guide for the Social Sciences. Thousand Oaks, CA: Sage Publications, Inc.

Wentzel, Kathryn R. 1991.”Social Competence at School: Relation Between Social Responsibility and Academic Achievement." Review of Educational Research 61(1):124.

Zell, Stacy K. 1997. Characterizing the Conversation: A Historical Re-view of Maria Montessori's Visits to the United States 1913-1918 (Doctoral Dissertation). 


\section{APPENDIX A: STUDIES ON ACADEMIC PERFROMANCE IN MONTESSORI SCHOOLS}

Brown, Katherine B. 2016. Evaluating the Effectiveness of Montessori Reading and Math Instruction for Third Grade African American Students in Urban Elementary Schools (Doctoral dissertation). Retrieved from ProQuest Dissertations \& Theses Global.

Cisneros, M. M. 1994. Multiple measures of the effectiveness of public school Montessori education in the third grade (Doctoral dissertation). Retrieved from UMI. (9424365).

Claxton, S. S. 1982. A comparison of student achievement, student self-concept, and parental attitude toward traditional and Montessori programs in a public school setting (Doctoral dissertation). Retrieved from UMI. (8217619).

Dawson, M. 1987. Minority student performance: Is the Montessori magnet school effective? Houston, TX: Texas Southern University. Retrieved from ERIC: http://files.eric.ed.gov/fulltext/ ED309881.pdf.

Dohrmann, Kathryn Rindskopf. 2003. Outcomes for students in a Montessori Program. A longitudinal Study of the Experience in the Milwaukee Public schools. AMI/USA.

Dohrmann, Kathryn Rindskopf, Tracy K. Nishida, Alan Gartner, Dorothy Kerzner Lipsky and Kevin J. Grimm. 2007. "High School Outcomes for Students in a Public Montessori Program." Journal of Research in Childhood Education 22(2):205-17.

Ervin, B., Wash, P. D., \& Mecca, M. E. 2010. "A 3-year study of self-regulation in Montessori and non-Montessori classrooms." Montessori Life 22(2): 22-31.

Fero, J. R. 1997. A comparison of academic achievement of students taught by the Montessori method and by traditional methods of instruction in the elementary grades (Doctoral dissertation). Retrieved from UMI (9729962).

Jones, Bobbie and Louise B. Miller. 1979. Four Preschool Programs: Their Lasting Effects. [Washington, DC]: Distributed by ERIC Clearinghouse.

Karnes, M. B., Shwedel, A. M., and Williams, M. B. 1983. A comparison of five approaches for educating young children from low-income homes. In Consortium for Longitudinal Studies (Ed.), Pp. 133-171 in As the twig is bent: Lasting effects of preschool programs. Hillsdale, NJ: L. Erlbaum Associates.

Lillard, Angeline and Nicole Else-Quest. 2006. “Evaluating Montessori Education.” Science 313 (5795): 1893-1894.

Lopata, Christopher, Nancy Wallace and Kristin Finn. 2005. "Comparison of academic achievement between Montessori and traditional education programs." Journal of Research in Childhood Education 20: 5-13. 
Mallett, Jan D. 2013. Academic Achievement Outcomes: Montessori and non-Montessori Public Elementary Students. (Doctoral dissertation). Retrieved from Texas AM University.

Mallett, Jan D. and Jennifer L. Schroeder. 2015. “Academic achievement outcomes: A comparison of Montessori and non-Montessori public elementary school students." Journal of Elementary Education 25(1): 39-53.

Manner, J. C. 2007. "Montessori vs. traditional education in the public sector: Seeking appropriate comparisons of academic achievement." Forum on Public Policy: A Journal of the Oxford Round Table 7(2). Retrieved from http://forumonpublicpolicy.com /papersspr07.html\#edufut.

Miller, Louis B., Jean L. Dyer, Harold Stevenson, Sheldon H. White. 1975. "Four preschool programs: Their dimensions and effects." Monographs of the Society for Research in Child Development 40 (5-6) Serial No. 162.

McDurham, R. 2011. A Comparison of Academic Achievement for Seventh and Eighth Grade Students from Montessori and non-Montessori School Programs (Doctoral Dissertation) Retrieved from ProQuest Dissertations \& Theses Global.

Miller, Louis B. and Rondeal P.Bizzell. 1983. "Long-Term Effects of Four Preschool Programs: Sixth, Seventh, and Eighth Grades.” Child Development 54(3): 727-741.

Miller, Louis B., and Rondeal P. Bizzell. 1984." Long-term effects of four preschool programs: Ninth- and tenth-grade results." Child Development 55: 1570-1587.

Moody, M. J., \& Riga, G. 2011. Montessori: Education for life. In L. Howell, C. W. Lewis, \& N. Carter (Eds.), Pp. 127-143 in Yes we can!: Improving urban schools through innovative education reform. Charlotte, NC: Information Age Publishing.

Peng, Hsin-Hui. 2009. A comparison of the achievement test performance of children who attended Montessori schools and those who attended non-Montessori schools in Taiwan. (Doctoral dissertation). Retrieved from ERIC (FirstSearch) (ED513608).

Salazar, Minerva. 2014. The Impact of Montessori Teaching on Academic Achievement of Elementary School Students in a Central Texas School District: A Casual-Comparative Inquiry (Doctoral dissertation). Retrieved from Texas AM University.

Sciarra, Dorothy June, \& Anne Dorsey 1976. "Nine-year follow-up study of Montessori education.” University of Cincinnati. Retrieved from ERIC: http://files.eric.ed.gov/ fulltext/ED121929.pdf.

Stodolsky, S. S. 1970. "Ancona Montessori research project for culturally disadvantaged children: Final report.” Retrieved from ERIC: http://files.eric.ed.gov/ fulltext/ED133066.pdf. 
Takacs, Carol and Alccilia Clifford. 1991. Marotta Montessori Schools of Cleveland Follow-Up Study of Urban Center Pupils. (Unpublished paper, Cleveland State University). 


\section{APPENDIX B: STUDIES ON SOCIAL COMPETENCE}

Diekmann, Marius and Sabine Gruehn. 2013. Fostering Students' Social Competence - A Comparison of Montessori and Traditional Schools' Impact at the end of Secondary Level 1. Creativity and Innovation in Educational Research.

Elias, Maurice J. and Norris M. Haynes. 2008. "Social Competence, Social Support, and Academic Achievement in Minority, Low-Income, Urban Elementary School Children.” School Psychology Quarterly 23(4): 474-495.

Frey, K. A., and W. Bos. 2012. "A psychometric analysis of a large-scale social competence inventory for elementary school children." JERO 4(1): 20-46.

Galindo, C., \& Fuller, B. 2010. "The social competence of Latino kindergartners and growth in mathematical understanding." Developmental Psychology 46:579-592.

Kayioi, Gokhan and Ozden Kuúcu. 2012.’Examination of Social Competence and School Adjustment of Primary School Children who had Pre-School Education with the Montessori Method."Journal of Teaching and Education 1(2): 399-405.

Lillard, Angeline and Nicole Else-Quest. 2006. "Evaluating Montessori Education.” Science 313 (5795): 1893-1894.

Magelinskaitė-Legkauskienè, Sarune, Visvaldas Legkauskas, Albina Kepalaitè. 2016. "Relative Importance of Social Factors Linked to Academic Achievement in the $1^{\text {st }}$ Frade." Social Welfare Interdisciplinary Approach 6 (2).

McClelland, M. M., Morrison, F. J., \& Holmes, D. L. 2000.”Children at risk for early academic problems: The role of learning-related social skills." Early Childhood Research Quarterly, 15(3): 307-329.

McClelland, Megan and Morrison, Frederick. 2003. "The emergence of learning-related social skills in preschool children." Early Childhood Research Quarterly 18: 206-224.

McClelland, M. M., Acock, A. C., \& Morrison, F. J. 2006. The impact of kindergarten learningrelated skills on academic trajectories at the end of elementary school. Early Childhood Research Quarterly, 21(4): 471-490.

Oades-Sese, Geraldine V., Giselle B. Esquivel, Pamela K. Kaliski, Lisetts Maniatis. 2011. “A Longitudinal Study of the Social and Academic Competence of Economically Disadvantaged Bilingual Preschool Children.” Developmental psychology 47: 747-764. 10.1037/a0021380. 
Stepp, S.D., D.A. Pardini, R. Loeber, N.A. Morris. 2011. "The relation between adolescent social competence and young adult delinquency and educational attainment among at-risk youth: the mediating role of peer delinquency." Can J Psychiatry 56(8): 457-465.

Valiente, Carlos, Nancy Eissenberg, Rg Haugen, Tracy L. Spinrad, Claire Hofer, Jeffrey Liew, and Anne Kupfer. 2011. "Children's Effortful Control and Academic Achievement: Mediation through Social Functioning." Early Educ Dev 22(3): 411-433.

Welsh M., Parke R. D., Widaman K., O’Neil R. 2001. Linkages between children's social and academic competence: a longitudinal analysis. J. Sch. Psychol. 39 463-482.

Wentzel, Kathryn R. 1991."Social Competence at School: Relation between Social Responsibility and Academic Achievement." Review of Educational Research 61(1):124. 


\section{APPENDIX C: DATA FOR DESCRIPTIVE ANALYSIS}

Math Performance by Individual Grade, Level, and Year in Percentages: MLI

\begin{tabular}{ccccc}
\hline Grades & \multicolumn{5}{c}{ MATH } & 6 \\
\hline L1ML16 & 3 & 4 & 5 & 30.60 \\
L2ML16 & 21.40 & 37.50 & 21.70 & 19.40 \\
L3ML16 & 17.90 & 22.50 & 26.10 & 33.30 \\
L4ML16 & 25.00 & 35.00 & 30.40 & 16.70 \\
L5ML16 & 28.60 & 5.00 & 21.70 & 0.00 \\
\hline
\end{tabular}

Math Performance by Individual Grade, Combined Levels, and Year in Percentages: MLI

\begin{tabular}{ccccc}
\hline Grades & \multicolumn{5}{c}{ MATH } & 6 \\
\hline & 3 & 4 & 5 & 30.60 \\
L1ML16 & 21.40 & 37.50 & 21.70 & 52.70 \\
L4-L3ML16 & 42.90 & 57.50 & 56.50 & 16.70 \\
\hline
\end{tabular}

Math Performance by Individual Grade, Level, and Year: MHI

\begin{tabular}{cccc}
\hline Grades & \multicolumn{4}{c}{ MATH } & 6 \\
\hline L1MH16 & 3 & 4 & 5 \\
L2MH16 & 9.10 & 10.50 & 0.00 \\
L3MH16 & 18.20 & 15.80 & 18.20 \\
L4MH16 & 36.40 & 26.30 & 27.30 \\
L5MH16 & 27.30 & 42.10 & 54.50 \\
\hline
\end{tabular}

Math Performance by Individual Grade, Combined Levels, and Year: MHI

\begin{tabular}{|c|c|c|c|c|}
\hline Grades & & MATH & & \\
\hline & 3 & 4 & 5 & 6 \\
\hline L1MH16 & 9.10 & 10.50 & & 0.00 \\
\hline L2-L3MH16 & 54.60 & 42.10 & & 45.50 \\
\hline L4- L5MH16 & 36.40 & 47.40 & & 54.50 \\
\hline
\end{tabular}


Math Performance by Individual Grade, Level, and Year: CLI

\begin{tabular}{ccccc}
\hline Grades & \multicolumn{5}{c}{ MATH } & 6 \\
\hline & 3 & 4 & 5 & 11.40 \\
L1CL16 & 8.60 & 6.50 & 3.20 & 36.40 \\
L2CL16 & 17.20 & 17.70 & 15.90 & 18.20 \\
L3CL16 & 20.70 & 29.00 & 38.10 & 29.50 \\
L4CL16 & 48.3 & 37.10 & 34.90 & 4.50 \\
L5CL16 & 5.20 & 9.70 & 7.90 & \\
\hline
\end{tabular}

Math Performance by Individual Grade, Combined Levels, and Year: CLI

\begin{tabular}{ccccc}
\hline Grades & \multicolumn{5}{c}{ MATH } & 6 \\
\hline & 3 & 4 & 5 & 11.40 \\
L1CL16 & 8.60 & 6.50 & 3.20 & 54.60 \\
L2-L3CL16 & 37.90 & 46.70 & 54.00 & 34.00 \\
L4-L5CL16 & 53.50 & 46.80 & 42.80 & \\
\hline
\end{tabular}

Math Performance by Individual Grade, Level, and Year: CHI

\begin{tabular}{ccccc}
\hline Grade & \multicolumn{5}{c}{ MATH } & 6 \\
\hline & 3 & 4 & 5 & 8.00 \\
L1CH16 & 3.60 & 2.00 & 6.90 & 8.00 \\
L2CH16 & 5.40 & 6.00 & 10.30 & 32.00 \\
L3CH16 & 10.70 & 22.00 & 17.20 & 44.00 \\
L4CH16 & 62.50 & 68.00 & 58.60 & 8.00 \\
L5CH16 & 17.90 & 2.00 & 6.90 & \\
\hline
\end{tabular}

Math Performance by Individual Grade, Combined Levels, and Year: CHI

\begin{tabular}{ccccc}
\hline Grade & \multicolumn{5}{c}{ MATH } & 5 \\
\hline & 3 & 4 & 6.90 & 8.00 \\
L1CH16 & 3.60 & 2.00 & 27.50 & 40.00 \\
L2-L3CH16 & 16.10 & 28.00 & 65.50 & 52.00 \\
L4-L5CH16 & 80.40 & 70.00 & &
\end{tabular}


ELA Performance by Individual Grade, Level, and Year: MLI

\begin{tabular}{ccccc}
\hline Grades & \multicolumn{5}{c}{ ELA } & 5 & 6 \\
\hline & 3 & 4 & 15.00 & 20.60 \\
\hline L1ML16 & 17.90 & 15.80 & 40.00 & 32.40 \\
L2ML16 & 17.90 & 42.10 & 30.00 & 29.40 \\
L3ML16 & 21.40 & 36.80 & 15.00 & 17.60 \\
L4ML16 & 42.90 & 5.30 & 0.00 & 0.00 \\
L5ML16 & 0.00 & 0.00 & & \\
\hline
\end{tabular}

ELA Performance by Individual Grade, Combined Levels, and Year: MLI

\begin{tabular}{ccccc}
\hline Grades & \multicolumn{5}{c}{ ELA } & 6 \\
\hline L1ML16 & 3 & 4 & 5 & 20.60 \\
L2-L3ML16 & 17.90 & 15.80 & 15.00 & 61.80 \\
L4-L5ML16 & 39.30 & 78.90 & 70.00 & 17.60 \\
\hline
\end{tabular}

ELA Performance by Individual Grade, Level, and Year: MHI

\begin{tabular}{ccccc}
\hline Grades & \multicolumn{5}{c}{ ELA } & 5 & 6 \\
\hline & 3 & 4 & N/A & 0.00 \\
L1MH16 & 4.20 & 13.30 & N/A & 9.10 \\
L2MH16 & 12.50 & 6.70 & N/A & 36.40 \\
L3MH16 & 29.20 & 6.70 & N/A & 54.50 \\
L4MH16 & 54.20 & 40.00 & N/A & 0.00 \\
L5MH16 & 0.00 & 33.30 & & \\
\hline
\end{tabular}

ELA Performance by Individual Grade, Combined Levels, and Year: MHI

\begin{tabular}{ccccc}
\hline Grades & \multicolumn{5}{c}{ ELA } & 5 & 6 \\
\hline & 3 & 4 & N/A & 0.00 \\
L1MH16 & 4.20 & 13.30 & N/A & 45.50 \\
L2-L3MH16 & 41.70 & 13.40 & N/A & 54.50 \\
\hline
\end{tabular}


ELA Performance by Individual Grade, Level, and Year: CLI

\begin{tabular}{ccccc}
\hline Grades & \multicolumn{5}{c}{ ELA } & 5 & 6 \\
\hline & 3 & 4 & 10.30 & 14.00 \\
L1CL16 & 13.30 & 3.20 & 22.40 & 39.50 \\
L2CL16 & 15.00 & 17.50 & 32.80 & 18.60 \\
L3CL16 & 20.00 & 28.60 & 32.80 & 20.90 \\
L4CL16 & 46.70 & 36.50 & 1.70 & 7.00 \\
L5CL16 & 5.00 & 14.30 & & \\
\hline
\end{tabular}

ELA Performance by Individual Grade, Combined Levels, and Year in Percentages: CLI

\begin{tabular}{ccccc}
\hline Grades & \multicolumn{5}{c}{ ELA } & 5 & 6 \\
\hline & 3 & 4 & 10.30 & 14.00 \\
L1CL16 & 13.30 & 3.20 & 55.20 & 58.10 \\
L2-L3CL16 & 35.00 & 46.10 & 34.50 & 27.90 \\
L4-L5CL16 & 51.70 & 50.80 & & \\
\hline
\end{tabular}

ELA Performance by Individual Grade, Level, and Year: CHI

\begin{tabular}{ccccc}
\hline Grades & \multicolumn{5}{c}{ ELA } & 5 \\
\hline & 3 & 4 & 3.30 & 12.00 \\
L1CH16 & 5.40 & 2.00 & 13.30 & 12.00 \\
L2CH16 & 0.00 & 8.00 & 20.00 & 36.00 \\
L3CH16 & 7.10 & 22.00 & 56.70 & 40.00 \\
L4CH16 & 69.60 & 56.00 & 6.70 & 0.00 \\
L5CH16 & 17.90 & 12.00 & & \\
\hline
\end{tabular}

ELA Performance by Individual Grade, Combined Levels, and Year in Percentages: CHI

\begin{tabular}{ccccc}
\hline Grades & \multicolumn{5}{c}{ ELA } & 5 & 6 \\
\hline & 3 & 4 & 3.30 & 12.00 \\
L1CH16 & 5.40 & 2.00 & 33.30 & 48.00 \\
L2-L3CH16 & 7.10 & 30.00 & 63.40 & 40.00 \\
L4-L5CH16 & 87.50 & 68.00 & & \\
\hline
\end{tabular}




\section{APPENDIX D: DATA ON SOCIAL COMPETENCE}

Social Competence by Individual Skills in Percentages: MLI

\begin{tabular}{cccccc}
\hline Skills & Question 1 & Question 2 & Question 3 & Question 4 & Average \\
\hline Cooperation & 40.00 & 40.00 & 60.00 & 40.00 & 45.00 \\
Responsibility & 40.00 & 60.00 & 40.00 & & 46.67 \\
Self-Control & 40.00 & 47.00 & 47.00 & & 44.67 \\
\hline
\end{tabular}

Social Competence by Individual Skills in Percentages: $\mathrm{MHI}$

\begin{tabular}{cccccc}
\hline \multicolumn{1}{c}{ Skills } & Question 1 & Question 2 & Question 3 & Question 4 & Average \\
\hline Cooperation & 47.00 & 47.00 & 59.00 & 53.00 & 51.50 \\
Responsibility & 41.00 & 65.00 & 41.00 & & 49.00 \\
Self-Control & 59.00 & 47.00 & 47.00 & & 51.00 \\
\hline
\end{tabular}

Social Competence by Individual Skills in Percentages: CLI

\begin{tabular}{cccccc}
\hline Skills & Question 1 & Question 2 & Question 3 & Question 4 & Average \\
\hline Cooperation & 42.00 & 42.00 & 50.00 & 58.00 & 48.00 \\
Responsibility & 58.00 & 61.00 & 55.00 & & 58.00 \\
Self-Control & 61.00 & 62.00 & 71.00 & & 64.67 \\
\hline
\end{tabular}

Social Competence by Individual Skills in Percentages: CHI

\begin{tabular}{cccccc}
\hline Skills & Question 1 & Question 2 & Question 3 & Question 4 & Average \\
\hline Cooperation & 42.00 & 53.00 & 42.00 & 53.00 & 47.50 \\
Responsibility & 58.00 & 89.00 & 84.00 & & 77.00 \\
Self-Control & 89.00 & 89.00 & 95.00 & & 91.00 \\
\hline
\end{tabular}

Social Competence in Montessori Schools in Percentages

\begin{tabular}{cccc}
\hline Skills & MLI & MHI & Average \\
\hline Cooperation & 45.00 & 51.50 & 48.25 \\
Responsibility & 46.67 & 49.00 & 47.84 \\
Self-Control & 44.67 & 51.00 & 47.84 \\
\hline
\end{tabular}


Social Competence in Conventional Schools in Percentages

\begin{tabular}{cccc}
\hline Skills & CLI & CHI & Average \\
\hline Cooperation & 48.00 & 47.50 & 47.75 \\
Responsibility & 58.00 & 77.00 & 67.50 \\
Self-Control & 64.67 & 91.00 & 77.84 \\
\hline
\end{tabular}




\section{APPENDIX E: DATA FOR COMPARATIVE ANALYSIS}

Math by School and Levels in Percentages

\begin{tabular}{ccccc}
\hline Level & MLI & MHI & CLI & CHI \\
\hline 1 & 27.8 & 6.53 & 7.43 & 5.13 \\
$4-5$ & 19.76 & 46.10 & 44.28 & 66.98 \\
\hline
\end{tabular}

Math in Montessori Schools, Combined Grades, and Combined Levels in Percentages

\begin{tabular}{cccc}
\hline Level & MLI & MHI & Montessori \\
\hline 1 & 27.8 & 6.53 & 17.17 \\
$4-5$ & 19.76 & 46.10 & 32.93 \\
\hline
\end{tabular}

Math in Conventional Schools, Combined Grades, and Combined Levels in Percentages

\begin{tabular}{cccc}
\hline Level & CLI & CHI & Conventional \\
\hline 1 & 7.43 & 5.13 & 6.28 \\
$4-5$ & 44.28 & 66.98 & 55.63 \\
\hline
\end{tabular}

ELA by School and Levels in Percentages

\begin{tabular}{ccccc}
\hline Level & MLI & MHI & CLI & CHI \\
\hline 1 & 17.33 & 5.83 & 10.20 & 5.68 \\
$4-5$ & 20.20 & 60.67 & 41.23 & 64.73 \\
\hline
\end{tabular}

ELA in Montessori Schools, Combined Grades, and Combined Levels in Percentages

\begin{tabular}{cccc}
\hline Level & MLI & MHI & Montessori \\
\hline 1 & 17.33 & 5.83 & 11.58 \\
$4-5$ & 20.20 & 60.67 & 40.44 \\
\hline
\end{tabular}

ELA in Conventional Schools, Combined Grades, and Combined Levels in Percentages

\begin{tabular}{cccc}
\hline Level & CLI & CHI & Conventional \\
\hline 1 & 10.20 & 5.68 & 7.94 \\
$4-5$ & 41.23 & 64.73 & 52.98 \\
\hline
\end{tabular}

